\title{
The relationship between neurocognition and social cognition with functional outcomes in schizophrenia: A meta-analysis
}

Citation for published version (APA):

Fett, A-K. J., Viechtbauer, W., Dominguez, M-G., Penn, D. L., van Os, J., \& Krabbendam, L. (2011). The relationship between neurocognition and social cognition with functional outcomes in schizophrenia: $A$ meta-analysis. Neuroscience and Biobehavioral Reviews, 35(3), 573-588.

https://doi.org/10.1016/j.neubiorev.2010.07.001

Document status and date:

Published: 01/01/2011

DOI:

10.1016/j.neubiorev.2010.07.001

Document Version:

Publisher's PDF, also known as Version of record

Document license:

Taverne

Please check the document version of this publication:

- A submitted manuscript is the version of the article upon submission and before peer-review. There can be important differences between the submitted version and the official published version of record.

People interested in the research are advised to contact the author for the final version of the publication, or visit the DOI to the publisher's website.

- The final author version and the galley proof are versions of the publication after peer review.

- The final published version features the final layout of the paper including the volume, issue and page numbers.

Link to publication

\footnotetext{
General rights rights.

- You may freely distribute the URL identifying the publication in the public portal. please follow below link for the End User Agreement:

www.umlib.nl/taverne-license

Take down policy

If you believe that this document breaches copyright please contact us at:

repository@maastrichtuniversity.nl

providing details and we will investigate your claim.
}

Copyright and moral rights for the publications made accessible in the public portal are retained by the authors and/or other copyright owners and it is a condition of accessing publications that users recognise and abide by the legal requirements associated with these

- Users may download and print one copy of any publication from the public portal for the purpose of private study or research.

- You may not further distribute the material or use it for any profit-making activity or commercial gain

If the publication is distributed under the terms of Article $25 \mathrm{fa}$ of the Dutch Copyright Act, indicated by the "Taverne" license above, 
Review

\title{
The relationship between neurocognition and social cognition with functional outcomes in schizophrenia: A meta-analysis
}

\author{
Anne-Kathrin J. Fett ${ }^{\mathrm{a}, c, \mathrm{~d}}$, Wolfgang Viechtbauer ${ }^{\mathrm{b}}$, Maria-de-Gracia Dominguez ${ }^{\mathrm{a}}$, \\ David L. Penn ${ }^{\mathrm{e}}$, Jim van Os ${ }^{\mathrm{a}, \mathrm{d}}$, Lydia Krabbendam ${ }^{\mathrm{c}, \mathrm{d}, *}$ \\ a Department of Psychiatry and Neuropsychology, School of Mental Health and Neuroscience, Maastricht University, Maastricht, The Netherlands \\ ${ }^{b}$ Department of Methodology and Statistics, School for Public Health and Primary Care, Maastricht University, Maastricht, The Netherlands

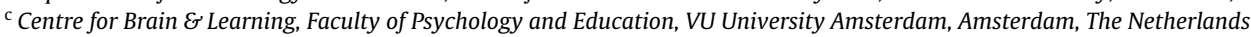 \\ ${ }^{d}$ Department of Psychosis Studies, Institute of Psychiatry, London, United Kingdom \\ e Department of Psychology, University of North Carolina Chapel Hill, United States
}

\section{A R T I C L E I N F O}

\section{Article history:}

Received 28 April 2010

Received in revised form 30 June 2010

Accepted 1 July 2010

\section{Keywords:}

Schizophrenia

Psychosis

Functional outcome

Community functioning

Quality of life

Neurocognition

Social cognition

\begin{abstract}
A B S T R A C T
The current systematic review and meta-analysis provides an extended and comprehensive overview of the associations between neurocognitive and social cognitive functioning and different types of functional outcome. Literature searches were conducted in MEDLINE and PsycINFO and reference lists from identified articles to retrieve relevant studies on cross-sectional associations between neurocognition, social cognition and functional outcome in individuals with non-affective psychosis. Of 285 studies identified, 52 studies comprising 2692 subjects met all inclusion criteria. Pearson correlations between cognition and outcome, demographic data, sample sizes and potential moderator variables were extracted. Forty-eight independent meta-analyses, on associations between 12 a priori identified neurocognitive and social cognitive domains and 4 domains of functional outcome yielded a number of 25 significant mean correlations. Overall, social cognition was more strongly associated with community functioning than neurocognition, with the strongest associations being between theory of mind and functional outcomes. However, as three-quarters of variance in outcome were left unexplained, cognitive remediation approaches need to be combined with therapies targeting other factors impacting on outcome.
\end{abstract}

(c) 2010 Elsevier Ltd. All rights reserved.

\section{Contents}

1. Introduction

2. Method.....

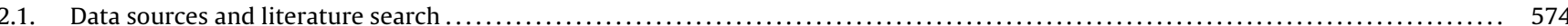

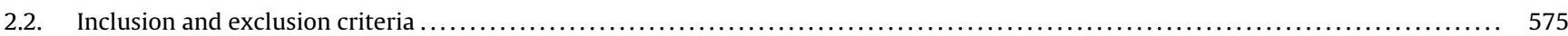

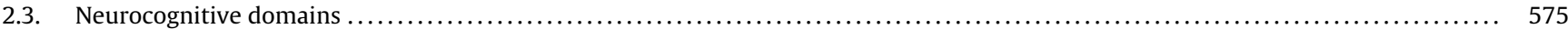

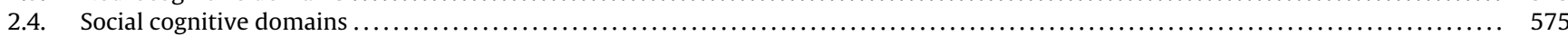

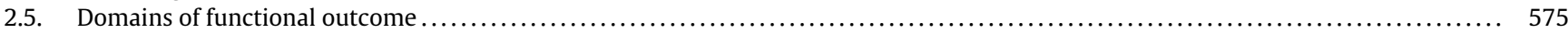

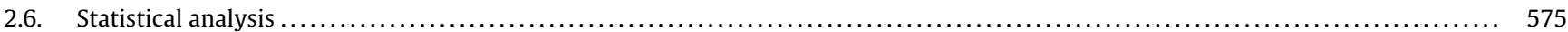

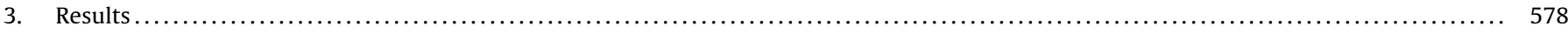

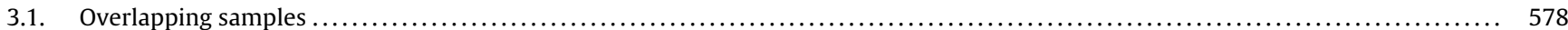

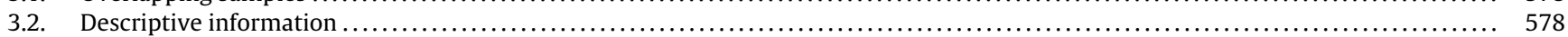

3.3. Meta-analyses of correlations between cognitive domains and outcome domains ....................................... 578

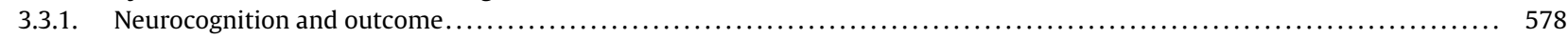

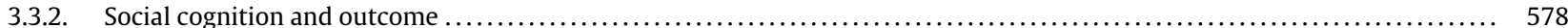

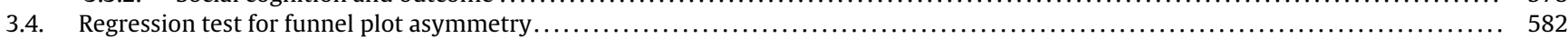

\footnotetext{
* Corresponding author at: Centre for Brain \& Learning, Faculty of Psychology and Education, VU University Amsterdam, Van der Boechorststraat 1, 1081 BT Amsterdam, The Netherlands. Tel.: +3120598 8859/3606; fax: +3120598 8745 .

E-mail address: AC.Krabbendam@psy.vu.nl (L. Krabbendam)
} 


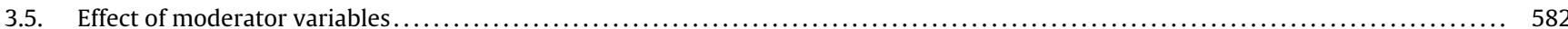

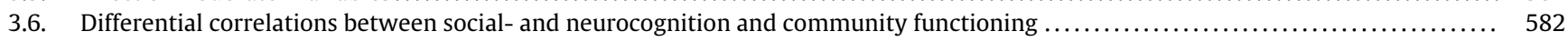

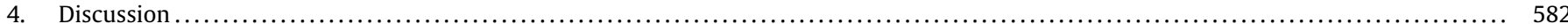

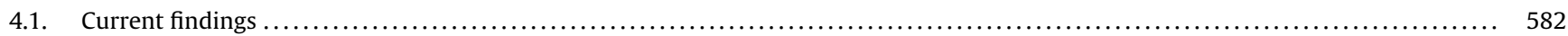

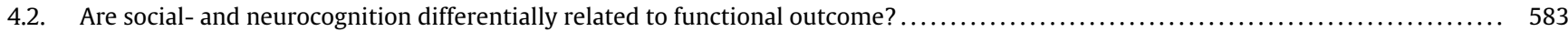

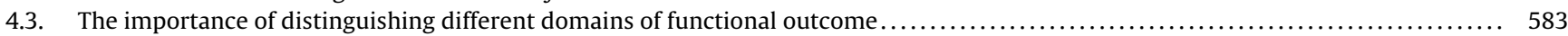

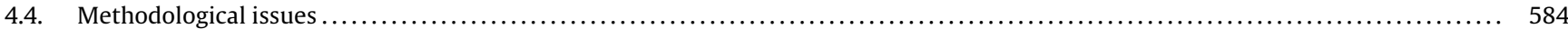

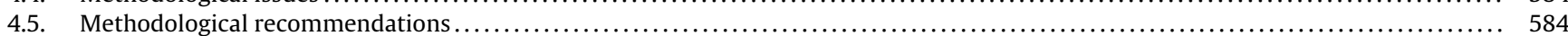

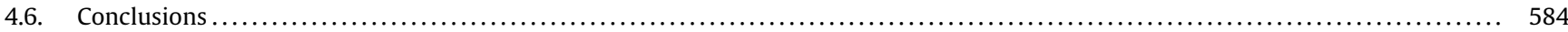

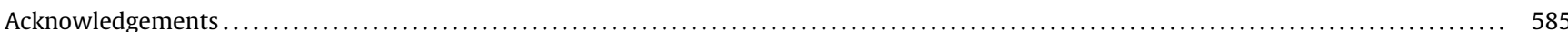

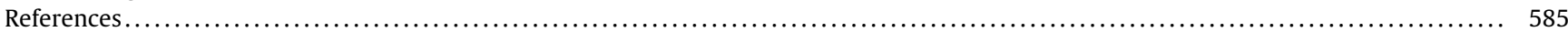

\section{Introduction}

Eight separable domains of cognitive impairment have been identified for schizophrenia according to the NIMH-Measurement and Treatment Research to Improve Cognition in Schizophrenia (MATRICS) consensus (Green et al., 2004b). Seven of these (processing speed, attention/vigilance, working memory, verbal learning and memory, visual learning and memory, reasoning and problem solving and verbal comprehension) belong to the domain of neurocognitive (NC) functioning. Social cognition (SC), referred to as the mental operations underlying social behavior, such as the interpretation of another person's intentions or emotions was identified as an additional domain. SC is a multi-dimensional construct that comprises functions such as: (1) emotional processing (EP); (2) social perception and knowledge (SP); (3) theory of mind (ToM) and (4) attributional bias (AS) (Bellack et al., 2007; Green et al., 2008; Penn et al., 1997, 2008). Obviously, processing socially relevant information also relies on NC (e.g., attention or memory); yet research shows that NC and SC are largely distinct domains (Allen et al., 2007; Pinkham et al., 2003; Sergi et al., 2007; Van Hooren et al., 2008).

Besides cognitive impairment, schizophrenia patients also experience severe deficiencies in their everyday functioning that are manifest within various areas, such as independent living, the instantiation and maintenance of interpersonal relationships or vocational functioning and leisure (Bellack et al., 2007; Couture et al., 2006; Flashman and Green, 2004; Green et al., 2008; Harvey et al., 2004). Finding potentially treatable determinants of functional outcome is one of the principal goals in schizophrenia research (Buchanan et al., 2005; Gold, 2004; Hofer et al., 2005; Holthausen et al., 2007). Being largely independent of other symptoms, present before the onset of illness and relatively stable over time, cognitive deficits fulfill the criteria of a potential treatment target (Bellack et al., 2007; Bora et al., 2009; Carlsson et al., 2006; Dominguez et al., 2009; Gold, 2004; Heinrichs and Zakzanis, 1998). Numerous studies corroborated that both SC and NC are related to everyday functioning in schizophrenia (Addington and Addington, 2000; Dickerson et al., 1996; Flashman and Green, 2004; Green, 1996; Holthausen et al., 2007). In fact, research has shown that NC may explain between $20 \%$ and $60 \%$ of variance in functional outcome and that it may be a better predictor than other characteristic symptoms of the illness (Green et al., 2000; Velligan et al., 1997). Three reviews have been conducted to identify whether specific NC deficits restrict the functioning of schizophrenia patients. A review of 16 studies indicated that verbal memory, executive functioning, and vigilance may be separately associated with outcome in terms of community functioning/daily activities, instrumental skills, social problem solving and psychosocial skill acquisition (Green, 1996). This finding was confirmed by a systematic review of 37 studies that investigated associations between four cognitive domains and a pooled functional outcome measure. Specifically, mean correlations ranged from 0.20 for vigilance, 0.23 for executive functioning and 0.29 for secondary verbal memory, to 0.40 for immediate verbal mem- ory (Green et al., 2000). A third review comprising 18 longitudinal studies showed that overall NC performance is also related to functional outcome more than 6 months later (Green et al., 2004a). This evidence established the potential of NC as treatment target.

Despite earlier evidence of being a determinant of daily functioning in schizophrenia (Corrigan and Toomey, 1995; Mueser et al., 1996) SC only came to the focus of attention more recently (Nuechterlein et al., 2004; Penn et al., 1997). A review of 22 studies on SC and functional outcome established associations between EP, SP and ToM and community functioning, social behavior in the milieu, social problem solving and social skills (Couture et al., 2006). Individual effect sizes ranged from zero to large. The overall magnitude of the associations, however, appeared small to modest. It has been suggested that SC functions as a mediator between NC and outcome (Addington et al., 2006a; Brekke et al., 2005; Meyer and Kurtz, 2009; Sergi et al., 2006; Vaskinn et al., 2008, 2009; Vauth et al., 2004). Still, SC also appears to be a valid predictor by itself, since it explains additional variance in outcome that cannot be accounted for by NC (Brekke et al., 2005; Bruene, 2005; Penn et al., 1996b; Pinkham and Penn, 2006; Waltheter et al., 2005). Other findings showed that SC may even exceed the value of NC and symptoms in explaining variance in outcome (Pijnenborg et al., 2009).

The issue of differential associations between SC and NC and functional outcome is important in order to identify specific cognitive domains as possible targets for treatment intervention (Gold, 2004). The current systematic review and meta-analysis was conducted to provide an extended and comprehensive overview of the specific SC-outcome and NC-outcome associations in non-affective psychosis. We examined associations between $12 \mathrm{NC}$ and SC domains and 4 domains of functional outcome and investigated differences between the associations of SC and NC and community functioning. To account for possible confounding, illness chronicity, inpatient status, age and gender were taken into account in the analysis.

\section{Method}

\subsection{Data sources and literature search}

Articles were identified through searches in the databases MEDLINE and PsychINFO that covered the period from January 1977 to August 2009. The keywords were psychosis, schizophrenia, or schizoaffective disorder combined with functional outcome, independent living skills, skills of daily living, community functioning, social functioning, work functioning, occupational functioning, vocational functioning, social skill, quality of life, community behavior, social behavior, life satisfaction, social adjustment, social dysfunction or employment and neuropsych* or neurocog* for NC and SP, emotional perception, affect perception, emotional recognition, attribution, AS, ToM, mentalising/mentalizing, social cognition, prosody, social knowledge, mind reading, social cue, or social judgment for SC. In addition, relevant articles were examined for undetected references (Couture et al., 2006; Green, 1996; Green et al., 2000, 2004a; 
Ikebuchi, 2007; Milev et al., 2005). The search yielded 285 potentially eligible articles that were inspected for inclusion.

\subsection{Inclusion and exclusion criteria}

The following criteria guided the inclusion of studies: (a) the sample consisted of patients with a diagnosis of non-affective psychosis according to an established criterion-based diagnostic system, i.e., the Diagnostic and Statistical Manual of Mental Disorder (APA, 1980, 1987, 1994, 2000), the research diagnostic criteria (Spitzer et al., 1978), the Schedule for Affective Disorders and Schizophrenia (Endicott and Spitzer, 1978), and the International Classification of Diseases (WHO, 1977, 1990). The study: (b) included participants aged 18-66 years; (c) used recognized cognitive tasks and outcome measures that could be classified into the current domains; (d) (or authors) provided all correlations between cognitive performance and outcome; (e) reported cross-sectional relationships. Studies that included patients with special characteristics that could affect cognitive performance (e.g., geriatric patients or patients with childhood psychosis) were excluded.

\subsection{Neurocognitive domains}

The NC domains included the seven cognitive factors identified by the MATRICS committee: (1) reasoning \& problem solving; (2) processing speed; (3) attention \& vigilance; (4) working memory; (5) verbal learning \& memory; (6) visual learning \& memory; (7) verbal comprehension (Buchanan et al., 2005; Nuechterlein et al., 2004). Although verbal fluency most commonly loads on the factor processing speed its tasks seem to be conceptually different from the other tasks that were used to measure processing speed. We therefore decided to include verbal fluency as an independent eighth factor (Heinrichs and Zakzanis, 1998; Nuechterlein et al., 2004). An often reported neurocognitive composite factor was incorporated as a ninth factor (Keefe et al., 2006a). Accordingly, suitable NC tests were grouped into nine domains (Table 1 ).

\subsection{Social cognitive domains}

The classification of the SC domains was based on the recent MATRICS recommendations (Green et al., 2005, 2008). Along these lines we grouped the tests into the most common cognitive domains in the field: (1) Theory of mind (ToM), (2) Emotional perception \& processing (EP); and (3) Social perception \& knowledge (SP; Table 1). Only one study investigated the attributional style-outcome association (Lysaker et al., 2004). Consequently, this domain could not be reviewed.

\subsection{Domains of functional outcome}

The included studies investigated multiple aspects of outcome. Some definitions, such as work functioning or living independently are rather direct indicators of real world functioning. Skill or competence based outcomes, such as role play performance, are more distal from how a person performs in reality but possibly more closely related to performance on NC and SC tests. To account for this variety we classified outcome into four previously described domains (Couture et al., 2006; Green, 1996; Green et al., 2000, 2004a; Harvey et al., 2007).

1. Community functioning encompasses a variety of behaviors and activities, such as independent living skills and social or work functioning that are direct indicators of everyday functioning. Most measures were rated by an interviewer.
2. Social behavior in the milieu mostly refers to observed behavior and comprises staff-ratings of the participants' behavior in different treatment or (in)patient settings.

3. Social problem solving refers to the ability to recognize everyday social problems and to generate respective solutions. The outcome is based on observed behavior.

4. Social skills consists of behavior based tests that assess interactional skills (e.g., eye contact, voice volume) in role-play tasks.

Social problem solving and social skills can be considered as intermediate variables rather than direct measures of functional outcome. Yet, research rarely reported intercorrelations with other outcome domains, which would have been required to test mediation or moderation. For that reason, we treated the two factors in line with the other outcome domains. The outcome domains, with their respective tests and parameters, are listed in Table 2.

\subsection{Statistical analysis}

Results were quantified in terms of correlations. In some cases higher scores reflected worse cognitive performance or outcome, in other cases lower scores reflected worse cognitive performance or outcome. Therefore all correlations were recoded so that positive correlations indicated associations between better cognitive performance and better functional outcome. If a study reported several cognition-outcome correlations within the same domains correlations were pooled. All correlations were transformed with Fisher's $r$-to- $z$ transformation before the meta-analytic methods were applied. Results from the meta-analysis were back-transformed into raw correlation metric whenever possible. Data extraction and calculations of effect sizes were performed independently by two authors (AKF \& MdGD). All analyses were carried out with the 'metafor' package (version 0.5-7) in the statistical software $R$ (version 2.10.0).

First, we conducted 48 individual meta-analyses on the correlations between all cognitive and outcome domain pairs. Analyses based on three or more correlations were considered. We used a random-effects model to account for heterogeneity and to obtain unconditional inferences about the distribution of population correlations (Hedges and Vevea, 1998; Leucht et al., 2009). The amount of heterogeneity in the true correlations was estimated with restricted maximum-likelihood estimation. For each of these individual meta-analyses, we report $k$ (number of studies), $\hat{\mu}_{\rho}$ (estimated average correlation in the population distribution), $C I$ (95\% confidence interval for $\left.\mu_{p}\right) ; p$ (p-value for the test $\left.H 0: \mu_{p}=0\right)$, and the results from the $Q$-test for heterogeneity. Additional indices of the amount of variability in the correlations were $\hat{\tau}^{2}$ (estimated amount of heterogeneity in the true (transformed) correlations), $\mathrm{H}^{2}$ (total variability in the observed (transformed) correlation coefficients/within-study variance due to sampling error), and $I^{2}$ (percentage of the total variability in the observed (transformed) correlation coefficients due to heterogeneity). A value of $I^{2}$ equal to 0 suggests the absence of heterogeneity, in which case the random-effects model simplifies to a fixed-effects model. In that case, $\hat{\mu}_{\rho}=\hat{\rho}$, where $\hat{\rho}$ denotes the estimated true (homogeneous) correlation.

We examined all meta-analyses and the correlations between all cognitive domains and the four functional outcome domains for publication bias with funnel plots and regression tests for funnel plot asymmetry (Sterne and Egger, 2005). Some samples contributed multiple correlations and dependencies were present. We did not model dependencies, as this would have required information on all intercorrelations between the cognitive dimensions. Consequently, the results of the funnel plot asymmetry tests for the four outcome domains have to be treated with some caution. 
Table 1

Cognitive domains, tests and parameters.

\begin{tabular}{|c|c|c|}
\hline Cognitive domain & Test & Parameters \\
\hline $\begin{array}{l}\text { 1. Reasoning and problem solving } \\
\text { (reported by } 25 \text { studies) }\end{array}$ & $\begin{array}{l}\text { Block design (Wechsler, 1981) } \\
\text { COGLAB WCST (Spaulding et al., 1989) } \\
\text { Nelson's Modified Card Sorting Test (Nelson, 1976) } \\
\text { Penn Conditional Exclusion Test (Kurtz et al., 2004) } \\
\text { Wisconsin Card Sorting Test (Heaton, 1981) } \\
\text { Standard Progressive Matrices (Raven, 1958) } \\
\text { Tower of London (ToL), Tower of Hanoi } \\
\text { Behavioral Assessment of the Dysexecutive Syndrome } \\
\text { (BADS; Wilson et al., 1996) } \\
\text { The Rule Shift Cards Test } \\
\text { The Action Program Test } \\
\text { Key Search Test } \\
\text { The Temporal Judgment Task } \\
\text { Zoo Map Test } \\
\text { Modified Six Elements Test }\end{array}$ & $\begin{array}{l}\text { Number of correctly chosen patterns } \\
\text { Number of preservative errors } \\
\text { Number of categories completed } \\
\text { (pooled if both were reported) } \\
\text { Number of completed designs } \\
\text { Number of steps to complete } \\
\text { Number of errors, time } \\
\text { Number of steps completed } \\
\text { Search strategy, time } \\
\text { Number of correct time estimations } \\
\text { Number of errors/places visited, time } \\
\text { Number of tasks attempted/rule } \\
\text { breaks, time }\end{array}$ \\
\hline $\begin{array}{l}\text { 2. Processing speed } \\
\text { (reported by } 14 \text { studies) }\end{array}$ & $\begin{array}{l}\text { COGLAB RT (Spaulding et al., 1989) } \\
\text { Digit Symbol Substitution Test (Wechsler, 1955) } \\
\text { Letter cancellation (Brickenkamp, 1978; Diller et al., } \\
\text { 1974) } \\
\text { Trail Making Test A and B (Reitan, 1958) }\end{array}$ & $\begin{array}{l}\text { Reaction time } \\
\text { Number of symbols correctly copied } \\
\text { Number of correct cancellations } \\
\text { Time to completion }\end{array}$ \\
\hline $\begin{array}{l}\text { 3. Attention and vigilance } \\
\text { (reported by } 16 \text { studies) }\end{array}$ & $\begin{array}{l}\text { Continuous Performance Test (CPT; Nuechterlein and } \\
\text { Dawson, 1984) and its variations } \\
\text { Degraded Stimulus-CPT (Nuechterlein and Asarnow, } \\
\text { 1992) } \\
\text { Penn-CPT (Kurtz et al., 2001) } \\
\text { Early visual processing masking procedure (Green et } \\
\text { al., 2003) } \\
\text { Span of apprehension (Asarnow et al., 1991) } \\
\text { Test of Everyday Attention (Robertson et al., 1994) }\end{array}$ & $\begin{array}{l}\text { Number or percentage of omissions } \\
\text { Number or percentage of commissions } \\
\text { Efficiency (true positive } \\
\text { responses/average reaction time) } \\
\text { Correct target location/identification }\end{array}$ \\
\hline 4. Working memory & Digit Span (DS) backward (Wechsler, 1955) & Number of digits recalled \\
\hline
\end{tabular}

(reported by 11 studies)

5. Verbal learning \& memory (reported by 26 studies)

6. Visual learning \& memory (reported by 11 studies)

7. Verbal comprehension (reported by 8 studies)

\section{Verbal fluency} (reported by 9 studies)
DS forward (Wechsler, 1955)

DS Distractibility Test (Olthmanns and Neale, 1975)

Brief Assessment of Cognition in Schizophrenia (BACS;

Keefe et al., 2004) digit sequencing

California Verbal Learning Test (Delis et al., 1987)

Hopkins Verbal Learning Test (Brandt, 1991)

Paired-Associate Learning subtest

Rey Auditory Verbal Learning Test (Rey, 1964)

Story recall

Logical Memory subtest Wechsler Memory Scale

Revised (Wechsler, 1987)

Word List Learning Test (WLT; Saan and Deelman, 1986)

Benton Facial Recognition Test (BFRT; Benton, 1992)

Brief Visual Memory Test (Benedict and Groninger, 1995)

Rey-Osterrieth Complex Figure Test (Rey, 1941)

WMS-R visual memory (Wechsler, 1987)

Multiple choice verbal comprehension test (Lehrl,

1976)

Vocabulary/information subtests of the WAIS

(Wechsler, 1955)

Wide Range Achievement Test Reading Scale

(Wilkinson, 1993)

BACS Category Instances Test

Controlled Word Association Test (COWAT; Benton,

1967)

Greek verbal fluency test (Kosmidis et al., 2004)

Letter and semantic fluency tests
Parameters

Number of categories completed

Number of completed designs

Number of steps to complete

Search strategy, time

Number of correct time estimations Number of errors/places visited, time

tasks attempted/rule

Reaction time

Number of symbols correctly copied

Time to completion

of omissions

Number of correct responses on either immediate or delayed recall

Number of items correct on either immediate or delayed recall

Number of figures correctly drawn

Percentage of recognized words

Number of correct words

Words from a certain category or words beginning with a certain letter 
Table 1 (Continued)

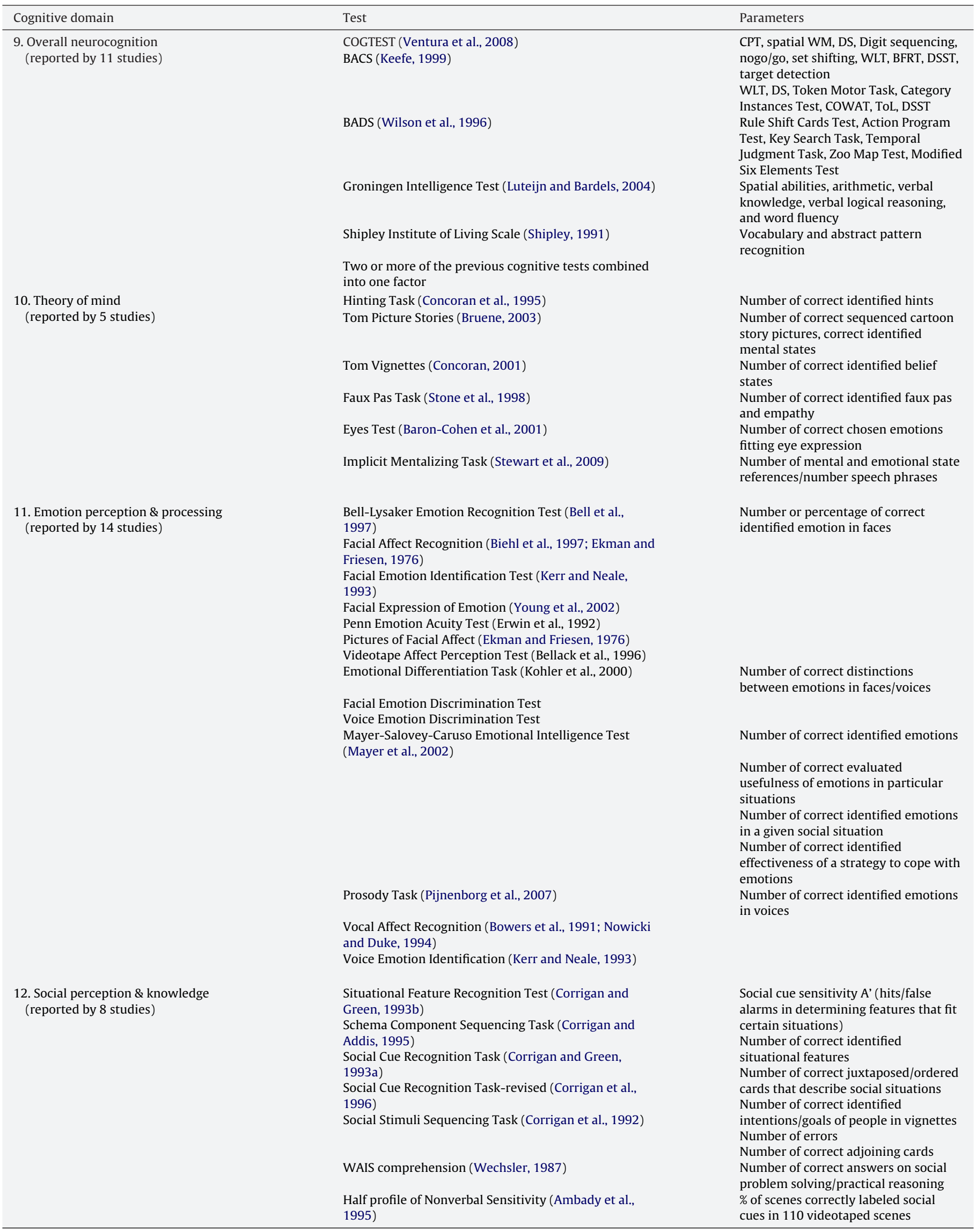


Second, illness chronicity, inpatient status, age, and male gender were taken into the analysis as moderators, as they may influence cognition-outcome associations (Andia et al., 1995; Dickerson et al., 1999; Fiszdon et al., 2008; Schennach-Wolff et al., 2009; Van Os et al., 1997). We used a mixed-effects meta-regression model to examine their influence. Again, restricted maximum-likelihood estimation was used to estimate the amount of residual heterogeneity (Leucht et al., 2009; Raudenbush, 1994). Due to incomplete information on moderator values within some studies, each moderator was examined individually. Results are expressed in terms of the estimated regression coefficients (i.e., $\hat{\beta}^{\prime}$ s) indicating by how much the average correlation (in the transformed units) is estimated to change with a 1-unit increase in the moderators. For age and illness chronicity one unit corresponds to one year, for male gender and inpatient status one unit corresponds to one percentage point. The corresponding $95 \% \mathrm{CI}$ for the true regression coefficient is given. Because the $r$-to- $z$ transformation is nonlinear, one cannot easily back-transform the slope of the regression coefficient into the raw correlation metric.

Third, we examined differences in the average correlations between the SC-community functioning and NC- community functioning associations. Several of the 33 studies that investigated community functioning examined correlations for the neurocognitive and social cognitive dimension. In order to account for dependencies between these correlations the covariance between the values was calculated (Steiger, 1980). All studies that investigated associations between community functioning and both SC and NC reported the required inter-correlations.

\section{Results}

In total 285 articles were considered for inclusion. Of these, 233 were excluded because the study: (a) examined longitudinal associations (12\%); (b) did not report correlations or associations between cognition and functional outcome (42\%); (c) reported non-parametric correlations (5\%); (d) only reported significant correlations/non-significant correlations could not be obtained (5\%); (e) reported cognitive or outcome measures that could not be classified into one of the current domains (9\%); (f) sample completely overlapped with another included sample (3\%); (g) included participants below 18 or above 66 years of age ( $8 \%$ ); (h) did not meet our criteria for diagnosis or included specific samples (e.g., geriatric patients; $2 \%$ ). (i) Finally, thirty-three studies could not be obtained, even after contacting the authors (14\%).

Fifty-two studies fulfilled all inclusion criteria. NC-outcome correlations were investigated by 48 studies. SC-outcome correlations were investigated by 21 studies, 17 of which also investigated NC and outcome. Table 3 shows the included studies along with sample sizes and characteristics.

\subsection{Overlapping samples}

Studies that fulfilled the inclusion criteria were examined for overlapping samples. Authors of studies performed at the same departments or catchment areas were asked for information on sample overlap. Overlap was dealt with in three ways:

(a) In case of overlapping samples and cognition-outcome associations within the same domains, the studies with the smaller sample size were excluded. This was the case for seven studies (Addington and Addington, 2008; Brekke et al., 2007; Horton, 2005; Kee et al., 2003; Keefe et al., 2006c; Penn et al., 1996b; Vaskinn et al., 2009).

(b) Studies with overlapping samples were included if cognitionoutcome correlations were reported for different domains. This was the case for ten studies (Addington et al., 2006a,b; Brekke et al., 2005, 2001; Hatashita Wong et al., 2002; Kee et al., 2009; Mueser et al., 1996; Nakagami et al., 2008; Penn et al., 1995a, 1996a).

(c) In case of two studies (Smith et al., 1999, 2002) with overlapping samples of equal size and identical cognition-outcome associations that were assessed by means of the same instruments a mean correlation of both studies was included.

\subsection{Descriptive information}

The included studies comprised at least 2692 individuals. To avoid counting a subject twice, the smaller studies of those with unknown degree of overlap were excluded from this calculation (total $n=3030$ ). The mean age was 36.26 years (range 25.9-47.5; $\mathrm{SD}=5.02$ ) and $68.7 \%$ of the sample was male. The average education was 12.3 years (range $9.1-14.3 ; \mathrm{SD}=1.14$ ). Overall, $87 \%$ were diagnosed with schizophrenia, $12 \%$ with schizoaffective disorder and $1 \%$ had other diagnoses in the non-affective psychosis spectrum. Five articles included samples of patients with schizophrenia or schizoaffective disorder but did not report exact numbers (Corrigan and Toomey, 1995; Meyer and Kurtz, 2009; Nakagami et al., 2008; Van Beilen et al., 2003; Velligan et al., 2004). The sample included $76.1 \%$ outpatients. The average illness duration was 12.78 years (range 3.4-22.5, SD=5.1). Other variables such as illness severity, medication dosage or type or the number of psychotic episodes may be relevant for the association between cognition and outcome but were reported by too few studies to be taken into account.

\subsection{Meta-analyses of correlations between cognitive domains and outcome domains}

Results for the meta-analyses are shown in Table 4. The analyses revealed a stable pattern of significant small to large mean correlations between both cognitive domains and functional outcome ( $\hat{\mu}_{\rho}=0.16$ to 0.48 , all $p$ 's $<0.001-0.016$ ), with only one non-significant association between attention $\&$ vigilance and social behavior in the milieu $\left(\hat{\mu}_{\rho}=0.19, p=0.21\right)$. The mean correlations were somewhat higher for SC than for NC. The squared maximum correlation indicates that SC may explain slightly more variance in outcome than NC (23.3\% vs. $15.2 \%)$. The moderators had little influence on NC-outcome associations and did not influence SC-outcome associations at all.

\subsubsection{Neurocognition and outcome}

The largest effect size was present for the association between verbal fluency and community functioning $\left(\hat{\mu}_{\rho}=0.32\right)$. Social behavior in the milieu had the strongest associations with verbal learning \& memory $\left(\hat{\mu}_{\rho}=0.32\right)$ and visual learning \& memory $\left(\hat{\mu}_{\rho}=0.30\right)$. The association between attention $\&$ vigilance and social behavior in the milieu, although into the expected direction, was not significant. Social problem solving had the strongest relationship with reasoning \& problem solving $\left(\hat{\mu}_{\rho}=0.29\right)$. Social skills was also strongly associated with reasoning \& problem solving $\left(\hat{\mu}_{\rho}=0.34\right)$, but showed the strongest association with attention $\&$ vigilance $\left(\hat{\mu}_{\rho}=0.39\right)$. The various NC-outcome associations differed in strength ( $\hat{\mu}_{\rho}=0.16$ to 0.39 ) but largely overlapping confidence intervals indicate that these differences may not reach statistical significance.

\subsubsection{Social cognition and outcome}

The largest mean correlation was present for the relationship between ToM and community functioning $\left(\hat{\mu}_{\rho}=0.48\right)$. The association between EP and social behavior in the milieu was $\hat{\mu}_{\rho}=0.22$. The meta-analysis for social skills and SP yielded an effect size of $\hat{\mu}_{\rho}=0.24$. No meta-analyses could be performed on social problem solving and any SC domain due to lack of data. The various 
Table 2

Domains of functional outcome, outcome measures and parameters.

\begin{tabular}{|c|c|c|}
\hline Domains of functional outcome & Outcome measure & Parameters \\
\hline \multirow[t]{21}{*}{$\begin{array}{l}\text { Community functioning } \\
\text { (reported by } 33 \text { studies) }\end{array}$} & $\begin{array}{l}\text { Clinical Global Impression of Cognition in Schizophrenia } \\
\text { (Bilder et al., 2003) }\end{array}$ & $\begin{array}{l}\text { Activities of daily living (ADL): instrumental functioning: } \\
\text { hygiene, hobbies, household chores. Social functioning: } \\
\text { e.g., socializing with peers and family, community } \\
\text { activities, dating }\end{array}$ \\
\hline & Community Adjustment Form (Test et al., 1991) & $\begin{array}{l}\text { Living situation, vocational, social functioning, activities of } \\
\text { daily living, family involvement, medication usage }\end{array}$ \\
\hline & Disability Assessment Scale (WHO, 1988) & $\begin{array}{l}\text { Personal care, family functioning, occupational } \\
\text { functioning, social functioning }\end{array}$ \\
\hline & Global Assessment Scale (Endicott et al., 1976) & Based on CAF interview \\
\hline & Global Assessment of Functioning (APA, 1994) & Global social functioning \\
\hline & Groningen Social Disability Scale (Wiersma et al., 1988) & $\begin{array}{l}\text { Friendship, housekeeping, citizenship, self care, leisure } \\
\text { activities, occupation/study }\end{array}$ \\
\hline & Indian Disability Evaluation Scale (2002) & $\begin{array}{l}\text { Self care interpersonal activities, social relationships, } \\
\text { communication, understanding, occupation }\end{array}$ \\
\hline & Independent Living Scales Inventory (Menditto et al., 1999) & $\begin{array}{l}\text { Personal management, hygiene, grooming, clothing, basic } \\
\text { skills, interpersonal skills, home maintenance, money } \\
\text { management, cooking, resource utilization, occupational } \\
\text { skills, medication management }\end{array}$ \\
\hline & Multnomah Community Ability Scale (Barker et al., 1994) & Adjustment to living and social competence \\
\hline & Lehman Work \& Productive Activity Scale (Lehman, 1997) & Work, school, volunteer work, and care of living \\
\hline & Life Assessment for the Mentally Ill (Iwasaki et al., 1994) & $\begin{array}{l}\text { Daily living, interpersonal relations, work skills, } \\
\text { endurance/stability, self-recognition }\end{array}$ \\
\hline & Life Skills Profile (Rosen et al., 1987) & $\begin{array}{l}\text { Communication, inter- and non-personal social behavior, } \\
\text { personal autonomy, self care }\end{array}$ \\
\hline & Performance Potential Inventory (Hogarty et al., 2008) & Functional disability \\
\hline & $\begin{array}{l}\text { Physical, cognitive, affective, social, economic, ego functions } \\
\text { (Bech, 1993) }\end{array}$ & $\begin{array}{l}\text { Social activity, speech disturbance, self care, community } \\
\text { skills }\end{array}$ \\
\hline & $\begin{array}{l}\text { Quality of Life Self Assessment Inventory (Skantze and Malm, } \\
\text { 1994) }\end{array}$ & $\begin{array}{l}\text { Housing, environment, knowledge \& education, contacts, } \\
\text { dependence, inner experiences, mental \& physical health, } \\
\text { leisure, work, religion }\end{array}$ \\
\hline & Quality of Life Scale (Heinrichs et al., 1984) & $\begin{array}{l}\text { Interpersonal relationships, capacity to form relationships, } \\
\text { instrumental role functioning, intra-psychic foundations, } \\
\text { common objects and activities }\end{array}$ \\
\hline & Quality of Life Interview (Lehmann, 1989) & $\begin{array}{l}\text { Performance \& satisfaction with circumstances, resources, } \\
\text { interpersonal relations }\end{array}$ \\
\hline & Role Functioning Scale (Goodman et al., 1993) & $\begin{array}{l}\text { Work, social functioning/relationships, independent } \\
\text { living/self care }\end{array}$ \\
\hline & Rehabilitation Evaluation Hall and Baker (Baker and Hall, 1988) & $\begin{array}{l}\text { Social activity, speech disturbance, speech skills, self care } \\
\text { skills, community skills }\end{array}$ \\
\hline & Social Functioning Scale (Birchwood et al., 1990) & $\begin{array}{l}\text { Social engagement, interpersonal communication, social } \\
\text { activities, competence, frequency of activities of daily } \\
\text { living, recreational activities, occupational activities }\end{array}$ \\
\hline & $\begin{array}{l}\text { UCSD Performance Based Skills Assessment (Patterson et al., } \\
\text { 2001a) }\end{array}$ & $\begin{array}{l}\text { Household chores, communication, finance, } \\
\text { transportation, planning recreational activities }\end{array}$ \\
\hline \multirow[t]{5}{*}{$\begin{array}{l}\text { Social behavior in the milieu } \\
\text { (reported by } 9 \text { studies) }\end{array}$} & $\begin{array}{l}\text { Nurse's Observation Scale for Inpatient Evaluation (Honigfeld } \\
\text { et al., 1966) }\end{array}$ & $\begin{array}{l}\text { Social competence, social interest, neatness, irritability, } \\
\text { pychoticism, psychomotor retardation }\end{array}$ \\
\hline & Social Adjustment Scale (Schooler and Weissman, 1979) & $\begin{array}{l}\text { Social behavior: frequency of leisure, social, peer, romantic } \\
\text { contact, activity in contacts }\end{array}$ \\
\hline & Social Dysfunction Index (Munroe-Blum et al., 1996) & $\begin{array}{l}\text { Public self, independent living, occupational functioning, } \\
\text { family relationships, important relationships other than } \\
\text { family, community, leisure/recreation, } \\
\text { acceptance/adherence to health regimes, communication, } \\
\text { locus of control }\end{array}$ \\
\hline & Social Behavior Schedule (Wykes and Sturt, 1986) & $\begin{array}{l}\text { Communication skills, social mixing, and hostile } \\
\text { interactions }\end{array}$ \\
\hline & Work Personality Profile (Bolton and Roessler, 1986) & $\begin{array}{l}\text { Work requirements: e.g., ability to relate to coworkers, } \\
\text { personal presentation: e.g., reaction to authority figures }\end{array}$ \\
\hline \multirow[t]{3}{*}{$\begin{array}{l}\text { Social problem solving } \\
\text { (reported by } 7 \text { studies) }\end{array}$} & $\begin{array}{l}\text { Assessment of Interpersonal Problem Solving Skills Test } \\
\text { (Donahoe et al., 1990) }\end{array}$ & $\begin{array}{l}\text { Interview \& role play test, videotaped interpersonal } \\
\text { scenes, problem identification (receiving), generation of } \\
\text { solutions (processing), enacting solutions (sending) }\end{array}$ \\
\hline & Response Evaluation Test (Mueser et al., 1993) & $\begin{array}{l}\text { Discriminate effective/ineffective social problem solving } \\
\text { behavior }\end{array}$ \\
\hline & Social Problem Solving Assessment (Sayers et al., 1995) & $\begin{array}{l}\text { Development of cognitive set, problem definition, } \\
\text { generating alternatives, decision making, verification }\end{array}$ \\
\hline \multirow[t]{3}{*}{$\begin{array}{l}\text { Social skills } \\
\text { (reported by } 9 \text { studies) }\end{array}$} & Conversation Probe Role Play Test (Penn et al., 1995a) & $\begin{array}{l}\text { Rated: clarity, fluency, affect, gaze, involvement, asking } \\
\text { questions. } 3 \text { min interaction with stranger }\end{array}$ \\
\hline & Role Play Test (Penn et al., 1995b) & $\begin{array}{l}\text { Rated: eye contact, shaking, long pauses, rocking, } \\
\text { fidgeting, restlessness, facial twitches, speed fluency. } 3 \mathrm{~min} \\
\text { interaction with stranger }\end{array}$ \\
\hline & Social Skills Performance Assessment (Patterson et al., 2001b) & $\begin{array}{l}\text { Rated: fluency, clarity, focus, affect, grooming, social } \\
\text { appropriateness, negotiation ability, persistence, overall } \\
\text { conversation/argument. Role play }\end{array}$ \\
\hline
\end{tabular}




\begin{tabular}{|c|c|c|c|c|c|c|c|c|c|c|c|c|}
\hline & Study & N & $\begin{array}{l}\text { Inpatients } \\
\%\end{array}$ & Men \% & $\begin{array}{l}\text { Illness chronicity } \\
\text { (years) }\end{array}$ & Age (years) & $\begin{array}{l}\text { Education } \\
\text { (years) }\end{array}$ & $\begin{array}{l}\text { Schizophrenia } \\
(\%)\end{array}$ & $\begin{array}{l}\text { Schizoaffective } \\
(\%)\end{array}$ & $\begin{array}{l}\text { Other non-affective } \\
\text { psychoses (\%) }\end{array}$ & $\begin{array}{l}\text { Cognitive } \\
\text { domain }\end{array}$ & $\begin{array}{l}\text { Functional outcome } \\
\text { domain }\end{array}$ \\
\hline 1 & Addington et al. (2006a) & 103 & & 70.4 & & 30.2 & & 82 & 1 & 17 & 9,12 & CF, SPS \\
\hline 2 & Addington et al. (2006b) & 103 & & 70.4 & & 30.2 & & 82 & 1 & 17 & 9,11 & $\mathrm{CF}$ \\
\hline 3 & Aksaray et al. (2002) & 57 & 0 & 66.7 & 14.5 & 38.8 & 11.3 & 100 & 0 & 0 & 1 & $\mathrm{CF}$ \\
\hline 4 & Bellack et al. (1994) & 27 & 100 & 55.5 & 8.4 & 30.3 & 12 & 100 & 0 & 0 & $7,4,5$ & SPS, SS \\
\hline 5 & Bora et al. (2006) & 50 & 0 & 66 & 9.1 & 30.6 & 11.5 & 100 & 0 & 0 & $7,2,6,10$ & $\mathrm{CF}$ \\
\hline 6 & Bowen et al. (1994) & 30 & 100 & 80 & & 36 & 12.9 & 100 & 0 & 0 & 3,4 & SPS \\
\hline 7 & Bozikas et al. (2006) & 40 & 0 & 62.5 & 11.9 & 36.3 & 10.9 & 100 & 0 & 0 & $1,2,5,6$ & $\mathrm{CF}$ \\
\hline 8 & Brekke et al. (2001) & 40 & 0 & 62.5 & 11.8 & 33.2 & 12.5 & 57.5 & 42.5 & 0 & 1 & $\mathrm{CF}$ \\
\hline 9 & Brekke et al. (2005) & 139 & 0 & 69.1 & 13.9 & 38.2 & 11.9 & 100 & 0 & 0 & 9,11 & CF, SBM \\
\hline 10 & Bruene (2005) & 23 & 100 & 78 & 12.3 & 38.8 & & 100 & 0 & 0 & $1,7,10,11$ & SBM \\
\hline 11 & Cohen et al. (2006) & 28 & 100 & 85.7 & & 33.6 & 12.2 & 100 & 0 & 0 & $\begin{array}{l}1,3,5,6,7 \\
11\end{array}$ & SBM, SS \\
\hline 12 & Corrigan and Toomey (1995) & 26 & 100 & 69 & 14.3 & 33.8 & 12.2 & & & & $1,3,4,5,12$ & SPS \\
\hline 13 & Eack and Keshavan (2008) & 58 & & 69 & 3.4 & 25.9 & & 66 & 34 & 0 & 9 & $\mathrm{CF}$ \\
\hline 14 & Fiszdon et al. (2008) & 151 & 0 & 78 & 20.2 & 42.8 & 13.2 & 69.5 & 30.6 & 0 & $1,2,4,5$ & $\mathrm{CF}$ \\
\hline 15 & Hatashita Wong et al. (2002) & 44 & 0 & 51 & 18 & 36 & & 60 & 40 & 0 & $\begin{array}{l}1,2,3,4,5 \\
7,8\end{array}$ & SPS \\
\hline 16 & Hooker and Park (2002) & 20 & 100 & 75 & 18.8 & 39.3 & 12.7 & 100 & 0 & 0 & 6,11 & SBM \\
\hline 17 & Horton and Silverstein (2007) & 31 & 35.5 & 71 & & 47 & & 77.4 & 22.6 & 0 & $3,6,5$ & $\mathrm{CF}$ \\
\hline 18 & Ihnen et al. (1998) & 26 & 0 & 57.6 & & 33.4 & 12.1 & 100 & 0 & 0 & 11,12 & SS \\
\hline 19 & Kee et al. (2009) & 50 & 0 & 62 & 10.2 & 34.4 & 14 & 100 & 0 & 0 & 11 & $\mathrm{CF}$ \\
\hline 20 & Keefe et al. (2006b) & 56 & 91.6 & 83.9 & & 35.1 & 11.7 & 100 & 0 & 0 & $1,2,4,5,8$ & $\mathrm{CF}$ \\
\hline 21 & Krishnadas et al. (2007) & 25 & 0 & 64 & 11.3 & 40.2 & 9.1 & 100 & 0 & 0 & $2,4,5,6$ & $\mathrm{CF}$ \\
\hline 22 & Laes and Sponheim (2006) & 39 & 0 & 74.4 & & 43.9 & 14.1 & 100 & 0 & 0 & $1,3,5,8,9$ & $\mathrm{CF}$ \\
\hline 23 & Lysaker and Davis (2004) & 65 & 0 & 100 & 22.5 & 47.5 & 12.2 & 41 & 24 & 0 & $1,5,7$ & $\mathrm{CF}$ \\
\hline 24 & Meyer and Kurtz (2009) & 53 & 0 & 72 & 12.2 & 35.1 & 12.9 & & & 0 & $1,3,5,11$ & SS \\
\hline 25 & Mueser et al. (1991) & 55 & 100 & 45.5 & & 33.2 & 11.5 & 61.8 & 38.2 & 0 & 5,6 & SS \\
\hline 26 & Mueser et al. (1995) & 38 & & & 15.2 & 38 & 12.1 & 73.7 & 26.3 & 0 & $5,6,7,8$ & SS \\
\hline 27 & Mueser et al. (1996) & 28 & 100 & 47 & 9.5 & 44.8 & 11 & 71.4 & 28.6 & 0 & 6,11 & SBM, SS \\
\hline 28 & Nakagami et al. (2008) & 120 & 0 & 62.9 & 13.7 & 38.3 & 12.2 & & & & $1,3,4,5,8$ & $\mathrm{CF}$ \\
\hline 29 & Nemoto et al. (2007) & 40 & 0 & 75 & 5.6 & 30.2 & 14 & 100 & 0 & 0 & $1,2,4,5,8$ & $\mathrm{CF}$ \\
\hline 30 & Penn et al. (1995a) & 38 & 100 & 55.3 & & 36.2 & & 92.1 & 7.9 & 0 & $1,2,3$ & sS \\
\hline 31 & Penn et al. (1996a) & 27 & 100 & 66.7 & & 33.7 & & 81.5 & 18.5 & 0 & $\begin{array}{l}1,2,3,11 \\
12\end{array}$ & SBM \\
\hline 32 & Pijnenborg et al. (2009) & 46 & 6.5 & 73.9 & 7 & 27.4 & & 100 & 0 & 0 & $\begin{array}{l}2,5,9,10 \\
11\end{array}$ & $\mathrm{CF}$ \\
\hline 33 & Pinkham and Penn (2006) & 49 & 0 & 57.1 & 10.4 & 33.2 & 14.3 & 71.4 & 24.5 & 4.1 & $\begin{array}{l}2,5,7,10 \\
11,12\end{array}$ & Ss \\
\hline 34 & Poole et al. (1999) & 26 & 0 & 54 & 15 & 40 & 14 & 100 & 0 & 0 & 9 & $\mathrm{CF}$ \\
\hline 35 & Poole et al. (2000) & 40 & 0 & 77.5 & & 41 & 13 & 90 & 10 & 0 & 11 & $\mathrm{CF}$ \\
\hline 36 & Revheim and Medalia (2004) & 162 & 53.7 & 62.3 & 14.1 & 37.2 & 11.1 & 67.3 & 32.7 & 0 & 5,12 & $\mathrm{CF}$ \\
\hline 37 & Revheim et al. (2006) & 38 & 63 & 74 & 18.6 & 39.2 & 11.5 & 76 & 24 & 0 & $1,3,5,6,8$ & $\mathrm{CF}$ \\
\hline 38 & Savilla et al. (2008) & 57 & 0 & 75.4 & & 36.1 & & 100 & 0 & 0 & $1,2,4,5,8$ & $\mathrm{CF}$ \\
\hline 39 & Sergi et al. (2006) & 75 & 0 & 92 & 21.2 & 46.7 & 13 & 100 & 0 & 0 & 3,12 & $\mathrm{CF}$ \\
\hline 40 & Smith et al. (1999) & 46 & 0 & 63 & 21 & 39 & & 57 & 43 & 0 & $1,3,4,5,6$ & $\mathrm{CF}, \mathrm{SBM}$ \\
\hline 41 & Smith et al. (2002) & 46 & 0 & 59 & 19 & 37 & & 61 & 39 & 0 & 4,5 & SBM \\
\hline 42 & Stewart et al. (2009) & 18 & & 94.5 & 8.6 & 35.7 & 11.5 & 83.3 & 11.1 & 5.6 & 10 & $\mathrm{CF}$ \\
\hline 43 & Stratta et al. (2009) & 20 & 0 & 85 & & 35.2 & 11 & 100 & 0 & 0 & 1 & $\mathrm{CF}$ \\
\hline 44 & Tyson et al. (2008) & 36 & 13.8 & 86.2 & 13 & 38 & & 100 & 0 & 0 & 1,3 & $\mathrm{CF}$ \\
\hline 45 & Van Beilen et al. (2003) & 52 & 46 & 75 & 3.8 & 27.6 & & & & & $1,3,5$ & $\mathrm{CF}$ \\
\hline 46 & Vaskinn et al. (2008) & 26 & 100 & 65.4 & 6.7 & 32.2 & 13 & 100 & 0 & 0 & 9,11 & SPS \\
\hline 47 & Vauth et al. (2004) & 133 & 100 & 64.7 & 6.6 & 28.8 & & 100 & 0 & 0 & $1,2,3,5,12$ & SBM \\
\hline 48 & Velligan et al. (2004) & 339 & 0 & 66.2 & & 41.2 & 10.9 & & & & 9 & SBM \\
\hline 49 & Ventura et al. (2008) & 33 & 0 & 66 & & 38.5 & 13.6 & 82 & 3 & 15 & 9 & $\mathrm{CF}$ \\
\hline 50 & Villalta Gil et al. (2006) & 113 & 0 & 68 & 18.9 & 41.6 & & 100 & 0 & 0 & 5,9 & $\mathrm{CF}$ \\
\hline 51 & Woonings et al. (2002) & 44 & 0 & 86.4 & 8.7 & 30.7 & & 100 & 0 & 0 & $1,3,5$ & $\mathrm{CF}$ \\
\hline 52 & Zanello et al. (2006) & 20 & 0 & 50 & 8.3 & 32.6 & & 80 & 20 & 0 & $1,2,5,6,8$ & SPS \\
\hline
\end{tabular}

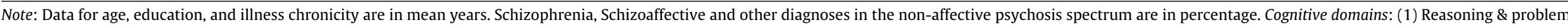

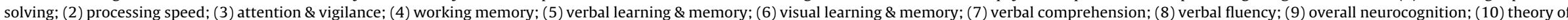

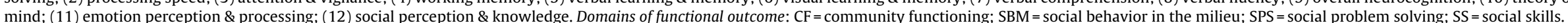


Table 4

Four $\times$ twelve meta-analyses of correlation coefficients between functional outcome and cognitive performance.

\begin{tabular}{|c|c|c|c|c|c|c|c|c|c|c|c|c|c|}
\hline \multirow[t]{2}{*}{ Outcome domain } & & \multicolumn{12}{|c|}{ Cognitive domain } \\
\hline & & $\begin{array}{l}\text { Reasoning \& } \\
\text { problem } \\
\text { solving }\end{array}$ & $\begin{array}{l}\text { Processing } \\
\text { speed }\end{array}$ & $\begin{array}{l}\text { Attention \& } \\
\text { vigilance }\end{array}$ & $\begin{array}{l}\text { Working } \\
\text { memory }\end{array}$ & $\begin{array}{l}\text { Verbal learning \& } \\
\text { memory }\end{array}$ & $\begin{array}{l}\text { Visual learning \& } \\
\text { memory }\end{array}$ & $\begin{array}{l}\text { Verbal } \\
\text { comprehension }\end{array}$ & $\begin{array}{l}\text { Verbal } \\
\text { fluency }\end{array}$ & $\begin{array}{l}\text { Overall } \\
\text { neurocognition }\end{array}$ & $\begin{array}{l}\text { Theory of } \\
\text { mind }\end{array}$ & $\begin{array}{l}\text { Emotion } \\
\text { perception \& } \\
\text { processing }\end{array}$ & $\begin{array}{l}\text { Social perception } \\
\text { \& knowledge }\end{array}$ \\
\hline \multirow{9}{*}{$\begin{array}{l}\text { Community } \\
\text { functioning }\end{array}$} & $k$ & 16 & 8 & 9 & 7 & 17 & 6 & - & 6 & 9 & 3 & 5 & 3 \\
\hline & $\hat{\mu}_{\rho}$ & 0.19 & 0.25 & 0.16 & 0.22 & 0.26 & 0.20 & & 0.32 & 0.25 & 0.48 & 0.31 & 0.41 \\
\hline & Q & 16.19 & 12.36 & 13.15 & $18.89^{* *}$ & $69.54^{* *}$ & 2.90 & & $20.01^{* *}$ & 4.58 & 0.81 & 1.67 & $16.85^{* *}$ \\
\hline & $\hat{\tau}^{2}$ & 0 & 0.02 & 0.01 & 0.04 & 0.04 & 0 & & 0.05 & 0 & 0 & 0 & 0.06 \\
\hline & $12 \%$ & 9.95 & 42.94 & 38.17 & 69.30 & 71.65 & 0.00 & & 75.90 & 0 & 0 & 0 & 86.59 \\
\hline & $\mathrm{H}^{2}$ & 1.11 & 1.75 & 1.62 & 3.26 & 3.53 & 1 & & 4.15 & 1 & 1 & 1 & 7.46 \\
\hline & $\mathrm{Cl} \mathrm{lb}$ & 0.12 & 0.13 & 0.04 & 0.05 & 0.15 & 0.07 & & 0.10 & 0.18 & 0.32 & 0.21 & 0.14 \\
\hline & $\mathrm{Cl} \mathrm{ub}$ & 0.26 & 0.37 & 0.27 & 0.38 & 0.37 & 0.33 & & 0.51 & 0.31 & 0.61 & 0.40 & 0.63 \\
\hline & $p$ & $<0.001$ & $<0.001$ & 0.01 & 0.01 & $<0.001$ & 0.003 & & 0.004 & $<0.001$ & $<0.001$ & $<0.001$ & 0.004 \\
\hline \multirow{9}{*}{$\begin{array}{l}\text { Social behavior in } \\
\text { the milieu }\end{array}$} & $k$ & 5 & - & 4 & - & 4 & 4 & - & - & - & - & 6 & - \\
\hline & $\hat{\mu}_{\rho}$ & 0.23 & & 0.19 & & 0.32 & 0.30 & & & & & 0.22 & \\
\hline & $Q$ & 2.06 & & $14.95^{* *}$ & & 4.84 & 3.47 & & & & & 3.08 & \\
\hline & $\hat{\tau}^{2}$ & 0 & & 0.07 & & 0.01 & 0.01 & & & & & 0 & \\
\hline & $1^{2} \%$ & 0 & & 74.16 & & 39.22 & 11.76 & & & & & 0 & \\
\hline & $\mathrm{H}^{2}$ & 1 & & 3.87 & & 1.65 & 1.13 & & & & & 1 & \\
\hline & $\mathrm{Cl} \mathrm{lb}$ & 0.11 & & -0.11 & & 0.15 & 0.10 & & & & & 0.10 & \\
\hline & $\mathrm{Cl}$ ub & 0.35 & & 0.45 & & 0.47 & 0.47 & & & & & 0.34 & \\
\hline & $p$ & $<0.001$ & & 0.21 & & $<0.001$ & 0.002 & & & & & $<0.001$ & \\
\hline \multirow{9}{*}{$\begin{array}{l}\text { Social problem } \\
\text { solving }\end{array}$} & $k$ & 3 & - & 3 & 4 & 4 & & - & - & - & - & - & - \\
\hline & $\hat{\mu}_{\rho}$ & 0.29 & & 0.25 & 0.25 & 0.26 & & & & & & & \\
\hline & Q & 0.73 & & 1.45 & 0.29 & 0.44 & & & & & & & \\
\hline & $\hat{\tau}^{2}$ & 0 & & 0 & 0 & 0 & & & & & & & \\
\hline & $I^{2} \%$ & 0 & & 0 & 0 & 0 & & & & & & & \\
\hline & $H^{2}$ & 1 & & 1 & 1 & 1 & & & & & & & \\
\hline & $\mathrm{Cl} \mathrm{lb}$ & 0.08 & & 0.05 & 0.07 & 0.07 & & & & & & & \\
\hline & $\mathrm{Cl} \mathrm{ub}$ & 0.47 & & 0.43 & 0.41 & 0.43 & & & & & & & \\
\hline & $P$ & 0.008 & & 0.02 & 0.007 & 0.003 & & & & & & & \\
\hline \multirow[t]{9}{*}{ Social skills } & K & 3 & - & 3 & & 7 & 5 & 5 & & & - & - & 5 \\
\hline & $\hat{\mu}_{\rho}$ & 0.34 & & 0.39 & & 0.18 & 0.28 & 0.24 & & & & & 0.24 \\
\hline & 0 & 1.04 & & 0.22 & & 8.54 & 5.22 & 3.81 & & & & & 0.72 \\
\hline & $\hat{\tau}^{2}$ & 0 & & 0 & & 0 & 0.02 & 0 & & & & & 0 \\
\hline & $12 \%$ & 0 & & 0 & & 0 & 30.81 & 0 & & & & & 0 \\
\hline & $H^{2}$ & 1 & & 1 & & 1 & 1.45 & 1 & & & & & 1 \\
\hline & $\mathrm{Cl} \mathrm{lb}$ & 0.17 & & 0.22 & & 0.06 & 0.07 & 0.07 & & & & & 0.10 \\
\hline & $\mathrm{Cl} \mathrm{ub}$ & 0.50 & & 0.53 & & 0.31 & 0.46 & 0.40 & & & & & 0.38 \\
\hline & $p$ & $<0.001$ & & $<0.001$ & & 0.005 & 0.008 & 0.02 & & & & & $<0.001$ \\
\hline
\end{tabular}

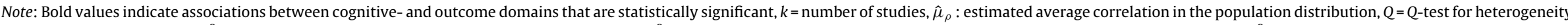

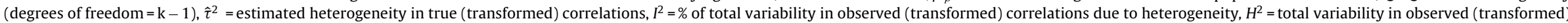

correlations/within-study variance due to sampling error; $\mathrm{Cl}=95 \%$ confidence interval for $\mu_{\mathrm{p}}, \mathrm{lb}=$ lower bound, ub $=$ upper bound, $p=p$-value for $H 0: \mu_{\mathrm{p}}=0$.

** Significant at $\alpha=0.01$. 


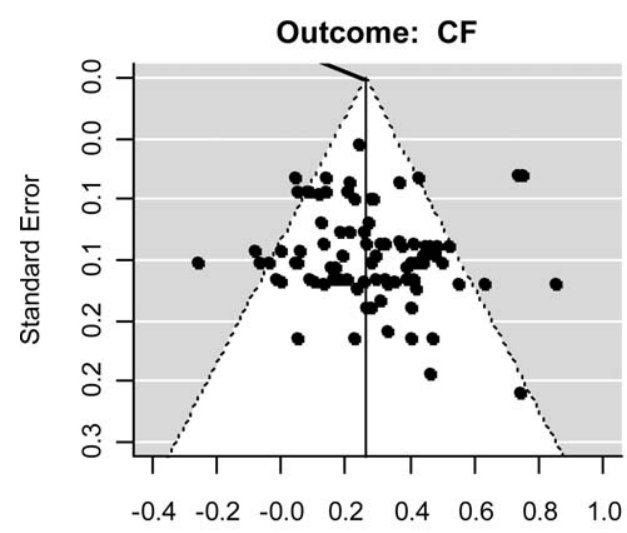

Transformed Correlation

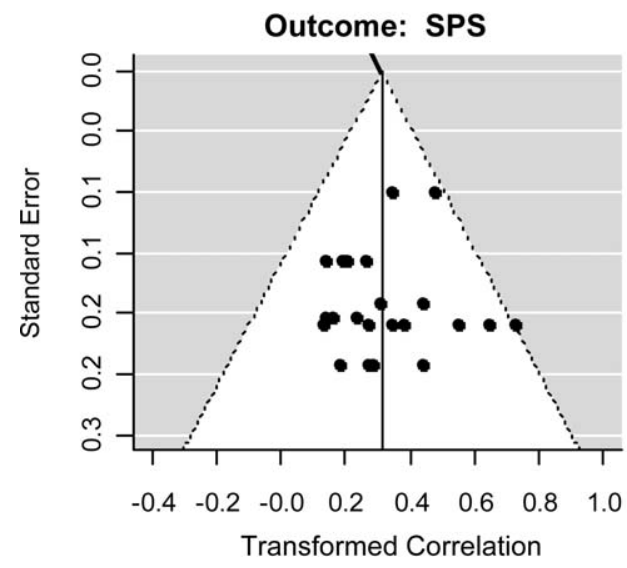

Outcome: SBM

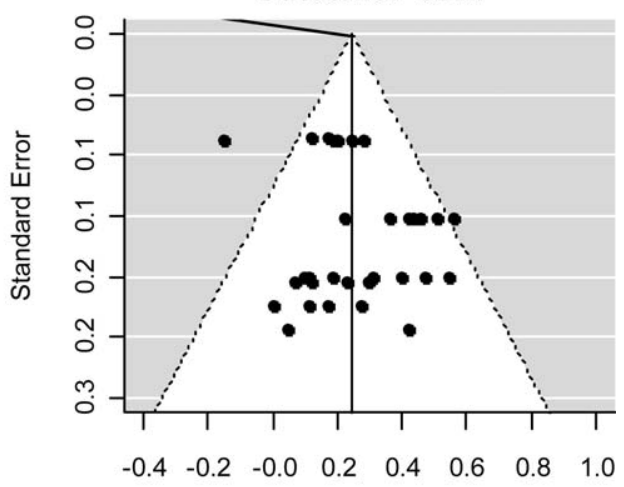

Transformed Correlation

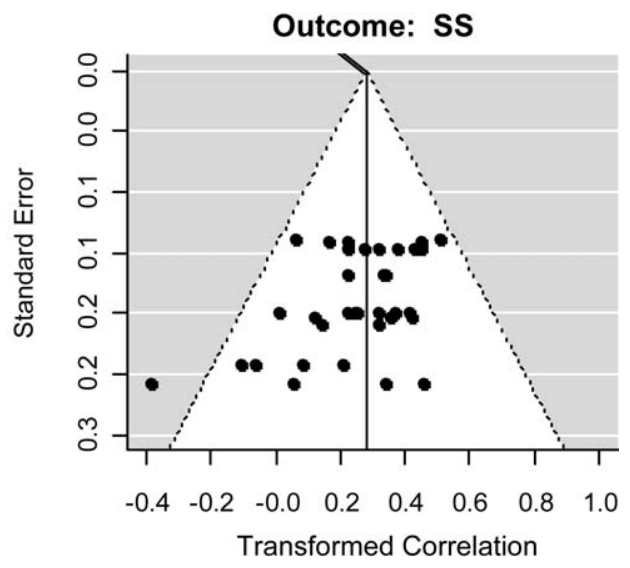

Fig. 1. Regression tests for funnel plot asymmetry for the associations between all cognitive domains within each domain of functional outcome.

SC-outcome associations differed in strength. Again, the largely overlapping confidence intervals indicate that these differences may not reach statistical significance in most cases.

\subsection{Regression test for funnel plot asymmetry}

Most regression tests for funnel plot asymmetry were nonsignificant. One significant result was present for the association between community functioning and SP $(p=0.03)$. However, only three observations were included in this analysis, hence any interpretation about funnel plot asymmetry should be made with caution. The funnel plots for each outcome dimension and the combined cognitive domains are shown in Fig. 1. The test for social skills was significant $(p=0.02)$. This finding was due to a single correlation of -0.37 . After removing the correlation from the model the test was no longer significant, suggesting that publication bias should not be a reason of concern in the current analysis.

\subsection{Effect of moderator variables}

The moderators did not account for the heterogeneity in the correlations between cognition and functional outcome. The effect of male gender was not significant for most meta-analyses (all $\hat{\beta}^{\prime} \mathrm{s}=$ -0.01 to 0.01 , all $p$ 's $=0.10-0.99$ ). An exception was the association between social skills and visual learning \& memory $(\hat{\beta}=0.01$, $p=0.03,95 \% \mathrm{CI}=0.00-0.01$ ), which became stronger with increasing percentage of males. Also age did not influence the average correlations between most cognitive domains and outcome (all $\hat{\beta}^{\prime} \mathrm{s}=-0.06$ to 0.95 , all $p$ 's $=0.09-0.95$ ), except for social behavior in the milieu and attention \& vigilance $\left(\hat{\beta}^{\prime} \mathrm{s}=0.06, p=0.03\right.$, $95 \% \mathrm{CI}=0.03-0.10)$ and social skills and visual learning $\&$ mem- ory $\left(\hat{\beta}^{\prime} \mathrm{s}=-0.04, p=0.04,95 \% \mathrm{CI}=-0.08\right.$ to -0.01$)$. Whereas the association between attention \& vigilance and social behavior in the milieu became stronger with increasing age, the association between visual learning \& memory and social skills became weaker with increasing age. There was no effect of inpatient status (all $\hat{\beta}^{\prime} s=-0.07$ to 0.03 , all $p$ 's $=0.06-0.96$ ), except for community functioning and verbal learning \& memory $(\hat{\beta}=0.004, p=0.02$, $95 \% \mathrm{CI}=0.00-0.01)$ and verbal fluency $(\hat{\beta}=0.01, p=0.01,95 \%$ $\mathrm{CI}=0.00-0.01)$. Both associations became stronger with increasing number of inpatients. Illness chronicity had no effect on the average correlations (all $\hat{\beta}^{\prime} \mathrm{s}=-0.07$ to 0.04 , all $p$ 's $=0.07-0.93$ ).

\subsection{Differential correlations between social- and neurocognition and community functioning}

Comparisons between all possible SC and NC community functioning combinations were computed. ToM was significantly stronger associated with community functioning than all NC domains (all p's <0.05), except verbal fluency. EP was more strongly associated with community functioning than attention \& vigilance $(p<0.05)$. There were no significant differences between other NC and SC community functioning combinations. Exact test values of the comparisons are given in Table 5.

\section{Discussion}

\subsection{Current findings}

NC and SC impairment were both substantially and consistently associated with functional outcome with small to medium 
Table 5

Comparisons between all neurocognitive and social cognitive domains and community functioning.

\begin{tabular}{|c|c|c|c|c|}
\hline Social cognitive domain & Neurocognitive domain & $k$ & $\begin{array}{l}\text { Estimated difference } \hat{\mu}_{\rho} \\
\text { neurocognition vs. social cognition }\end{array}$ & $P$ \\
\hline \multirow[t]{9}{*}{ Theory of mind } & Reasoning \& problem solving & 19 & 0.32 & $<0.001$ \\
\hline & Processing speed & 9 & 0.24 & 0.03 \\
\hline & Attention \& vigilance & 12 & 0.36 & 0.002 \\
\hline & Working memory & 10 & 0.29 & 0.002 \\
\hline & Verbal learning \& memory & 19 & 0.24 & 0.03 \\
\hline & Visual learning \& memory & 8 & 0.31 & 0.005 \\
\hline & Verbal comprehension & 4 & 0.31 & 0.01 \\
\hline & Verbal fluency & 9 & 0.19 & 0.20 \\
\hline & Overall neurocognition & 11 & 0.24 & 0.01 \\
\hline \multirow[t]{9}{*}{ Emotion perception \& processing } & Reasoning \& problem solving & 21 & 0.12 & 0.06 \\
\hline & Processing speed & 12 & 0.06 & 0.47 \\
\hline & Attention \& vigilance & 14 & 0.16 & 0.05 \\
\hline & Working memory & 12 & 0.08 & 0.39 \\
\hline & Verbal learning \& memory & 21 & 0.04 & 0.55 \\
\hline & Visual learning \& memory & 7 & 0.11 & 0.30 \\
\hline & Verbal comprehension & 11 & -0.01 & 0.89 \\
\hline & Verbal fluency & 11 & 0.11 & 0.20 \\
\hline & Overall neurocognition & 11 & 0.06 & 0.25 \\
\hline \multirow[t]{9}{*}{ Social perception \& knowledge } & Reasoning \& problem solving & 19 & 0.24 & 0.12 \\
\hline & Processing speed & 11 & 0.18 & 0.28 \\
\hline & Attention \& vigilance & 11 & 0.28 & 0.08 \\
\hline & Working memory & 10 & 0.21 & 0.23 \\
\hline & Verbal learning \& memory & 19 & 0.16 & 0.30 \\
\hline & Visual learning \& memory & 9 & 0.24 & 0.16 \\
\hline & Verbal comprehension & 5 & 0.23 & 0.19 \\
\hline & Verbal fluency & 9 & 0.10 & 0.57 \\
\hline & Overall neurocognition & 12 & 0.18 & 0.25 \\
\hline
\end{tabular}

$k=$ number of studies.

range effect sizes. The strength of the associations between the 12 cognitive domains and the 4 outcome domains were largely independent of age, gender, illness chronicity and inpatient status. The magnitudes of the associations between NC and outcome were in line with what has been reported by the previous reviews (Green, 1996; Green et al., 2000, 2004a). Community functioning was most strongly associated with verbal fluency, followed by verbal learning \& memory and processing speed. Social behavior in the milieu had the strongest associations with verbal learning \& memory and visual learning \& memory. Social problem solving was most strongly related to reasoning \& problem solving and social skills had the strongest associations with attention \& vigilance. The results indicate that different neurocognitive functions are somewhat differentially related to different domains of functional outcome with magnitudes ranging from $\hat{\mu}_{\rho}=0.16$ to 0.39 . However, it is uncertain to what degree these differences have practical significance, given the often small differences in effect sizes and overlapping confidence intervals.

The associations between SC and outcome were in the upper small to large range, with the largest effect size for ToM, followed by SP, and EP. An earlier descriptive review established associations between ToM, EP and SP and most outcome domains (Couture et al., 2006). Our findings support and quantify the previous results and suggest small differences between mean effect sizes of the relations between the heterogeneous SC domains and outcome. Even though potentially meaningful, the statistical and practical significance of these differences is doubted by overlapping confidence intervals and the relatively small number of reviewed studies.

\subsection{Are social- and neurocognition differentially related to functional outcome?}

SC appeared to be more strongly related to community functioning than NC. The overall neurocognitive factor accounted for $6 \%$ of the variance in community functioning, while the amount of variance that could be explained by the average SC domains was $16 \%$. Comparisons between all NC and SC domains and community functioning indicated that this difference was specifically due to stronger associations with ToM. This finding is in line with the suggestion that SC, despite likely having neurocognitive underpinnings, does explain unique variance in outcome (Brekke et al., 2005; Penn et al., 1997; Pinkham et al., 2003). Due to its proximity to community functioning (i.e., interpersonal relations, work functioning), SC functioning might be an even more important treatment target than NC functioning.

Fewer studies could be reviewed for the outcome domains social behavior in the milieu, social problem solving and social skills. The associations between SC and the more performance based outcome domains, which at face value are expected to rely on SC abilities, did not appear different from their associations with the NC domains. However, this finding is based on a comparison with two mean correlations between SC and outcome (e.g., social behavior in the milieu-EP and social skills-SP) only and warrants cautious interpretation. Within NC, verbal learning \& memory, reasoning \& problem solving, and attention \& vigilance showed the strongest associations with social behavior in the milieu, social problem solving and social skills, respectively. Yet again, the finding is based on few studies. Clearly, more research is needed to unravel whether specific cognitive functions are differentially related to functional outcome in the domains social behavior in the milieu, social problem solving and social skills and whether the strength of the associations differs between the NC and SC domains.

\subsection{The importance of distinguishing different domains of functional outcome}

The strength of the association between the specific cognitive functions and functional outcome are clearly dependent on how one operationalizes functional outcome. Performance based 
assessments were thought to provide the theoretically most relevant link to SC and NC because they assess what an individual is capable of doing without being influenced by external factors (Harvey et al., 2007). Other aspects of outcome, such as work or managing relationships that are comprised in community functioning, might be confounded by factors as social support, finances or personal resources (Couture et al., 2006). ToM had stronger associations with community functioning than the other cognitive domains, indicating that ToM may be a specific determinant of performance on broad based real world tasks. ToM and other SC abilities may also be important in achieving social support and personal resources, which both may influence real world outcome more than $\mathrm{NC}$ abilities. In this case one would also expect stronger associations between functional outcome in the domain social behavior in the milieu and SC, as compared to NC. Conversely, deficits in both cognitive domains may limit understanding and performance on social problem solving and social skills tasks. Whereas problem analysis and decision making may rely heavily on executive functioning, interpreting a given situation and identifying the appropriate solution may rather require social knowledge.

\subsection{Methodological issues}

Some methodological issues are important when considering the current findings. First, cognitive tests may vary in terms of sensitivity, which may be problematic in view of the generalized cognitive deficit in schizophrenia (Chapman and Chapman, 1978; Jonides and Nee, 2005; Miller et al., 1995). That is, the difference between performance of patients with schizophrenia and healthy controls will be greater for tasks with higher sensitivity and variance, regardless of differences in true ability. Such variation may result in different likelihoods of correlating with other parameters, such as functional outcome.

Second, several tests appear to tap functioning in various cognitive domains. We tried to overcome this problem by grouping tasks according to the results of factor analyses (Nuechterlein et al., 2004). With regard to SC tasks, no such well-defined guidelines were available. The tasks are heterogeneous in nature and their psychometric properties are rarely investigated and warrant more research (Bora et al., 2009). As for cognition, well-defined measures are also required for functional outcome (Harvey and Bellack, 2009). Our results showed that associations with cognition are depending on the specific definitions of outcome, which also bring along their own limitations and advantages. More research is therefore needed to find reliable and less heterogeneous indices of real world functioning (Burns and Patrick, 2007). In addition, research should investigate which aspects of outcome are sensitive to changes in cognition. Crucial steps in doing so have recently been made, for example, with the VALERO expert survey (Leifker et al., 2009).

Third, next to the included moderators, many other variables that are relevant to the cognition-outcome relationship (e.g., illness severity, pharmacological treatment, history of symptoms, genetic vulnerability or comorbidity) could not be examined due to underreporting. In addition, the necessary exclusion of a number of studies with incomplete information may have resulted in sample restriction.

Fourth, it is important to note that the current cross sectional data do not allow for conclusions about causality. On theoretical grounds, it seems likely that cognitive performance influences outcome, but at the same time, outcome may also influence cognition. Negative social experiences, for instance, may drive the development of maladaptive social schemas or attribution styles. A deprived surrounding or an unhealthy lifestyle may influence NC.

\subsection{Methodological recommendations}

Because of methodological inconsistencies and omission of important study details in potentially includable articles, the current meta-analysis could only include about one fifth of the possible total. This raises a number of issues that should be considered in future research. First, in order to be able to conduct good quality meta-analyses, future studies on cognition-outcome associations should always report the values of all non-significant and significant correlations.

Second, future studies should also report the intercorrelations between the test scores on all utilized neurocognitive, social cognitive and functional outcome measures, as these inter-correlations are a prerequisite for pooling of data. The availability of intercorrelations would allow for the comparison of cognition-outcome associations between the global factors, while accounting for conceptual overlap. Besides, intercorrelations are also required to test specific statistical models, such as mediation, which are of great interest because of the importance of SC functions as a possible key mediator between NC and functional outcome (Addington et al., 2006a).

Third, a couple of studies had to be excluded from the current meta-analysis because they used cognitive or outcome measures that could not be classified into one of the current domains. In order to make research comparable, future studies should adhere to guidelines consistent with those that have been brought forward by the MATRICS committee and with those of the NIMH Initiative Cognitive Neuroscience Treatment Research to Improve Cognition in Schizophrenia (CNTRICS; Carter and Barch, 2007). Clearly, more guidelines and standardization are needed especially with regard to the social cognitive domain.

Fourth, future studies on cognition-outcome associations should also make sure to always report standardized measures of psychotic symptoms, so that these can be taken into account as potential moderators of the cognition-outcome relationships.

Fifth, it would be desirable if future studies reported correlations between specific cognitive sub-domains and functional outcome instead of correlations between aggregates thereof. Finally, a couple of longitudinal studies had to be excluded from the current meta-analysis because they did not report baseline correlations between cognition and outcome. Future longitudinal research on cognition-outcome associations should also consider reporting such information.

\subsection{Conclusions}

The current findings show that SC is related to functional outcomes, perhaps stronger than NC. However, to guide the development of specific interventions to improve functional outcome further knowledge is needed regarding NC and SC-outcome associations, especially for outcome categories other than community functioning. Several studies have demonstrated that the social cognitive deficits of schizophrenia are modifiable through brief experimental manipulations or psychosocial interventions (Horan et al., 2008, 2009; Roberts and Penn, 2010). Future clinical trials are challenged to further investigate whether improving individual cognitive domains, such as ToM can also improve functional outcome. Given their potential functional significance, the different SC domains and their assessment warrant specific attention (i.e., validation and standardization of the specific SC tasks and their sensitivity to change or the responsiveness of the different cognitive functions to specific interventions). Finally, it should be noted that both NC and SC leave the bulk of the variance in outcome unexplained. The data show that even the most comprehensive set of cognitive factors can only explain a certain amount of variance in functional outcome of patients with schizophrenia. Accordingly, 
poor functional outcome must also be present in patients with little impaired cognitive functioning. Though possibly significant to a specific subgroup of patients, cognitive interventions may only be able to improve outcome to a small or medium extent (McGurk et al., 2007). There is support for the hypothesis that the relationship between cognition and functional outcome is partially mediated by negative symptoms. Negative symptoms are associated with both cognitive factors and appear to explain $17.6 \%$ of variance in outcome (Ventura et al., 2009). In addition, many other factors such as meta-cognition, motivation or social discomfort appear to influence the associations between cognition and functional outcome (Bell et al., 2009; Gard et al., 2009; Koren et al., 2006). This highlights the multifactorial causation of poor functional outcome in psychosis and stresses the additional need to quest for other rate limiting factors that can account for the unexplained variance in functional outcome.

\section{Acknowledgements}

Funding/support: Preparation of this article was supported by a VIDI grant from the Netherlands Organization for Scientific Research to Dr. Lydia Krabbendam.

Conflicts of interest/financial disclosure: Anne-Kathrin J. Fett, Dr. Maria-de-Gracia Dominguez, Dr. Wolfgang Viechtbauer and Dr. Lydia Krabbendam: none to disclose. Dr. Jim van Os reported research support by Eli Lilly, GSK, Organon, BMS, and AstraZeneca and speaker support by Eli Lilly, BMS, Lundbeck, Organon, JanssenCilag, and AstraZeneca; Dr. David L. Penn reported research funding, consulting fees, advisory board payments, and lecture or educational fees from Bristol-Myers Squib, Eli Lilly, Janssen, Johnson and Johnson, Repligen and a NIMH grant (NIMH 1-R34-MH080010-01; Social Cognition and Interaction Training for Schizophrenia).

\section{References}

Addington, J., Addington, D., 2000. Neurocognitive and social functioning in schizophrenia: a 2.5 year follow-up study. Schizophr. Res. 44, 47-56.

Addington, J., Addington, D., 2008. Social and cognitive functioning in psychosis. Schizophr. Res. 99, 176-181.

Addington, J., Saeedi, H., Addington, D., 2006a. Facial affect recognition: a mediator between cognitive and social functioning in psychosis? Schizophr. Res. 85, $142-150$.

Addington, J., Saeedi, H., Addington, D., 2006b. Influence of social perception and social knowledge on cognitive and social functioning in early psychosis. Br. J. Psychiatry 189, 373-378.

Aksaray, G., Oflu, S., Kaptanoglu, C., Bal, C., 2002. Neurocognitive deficits and quality of life in outpatients with schizophrenia. Prog. Neuropsychopharmacol. Biol. Psychiatry 26, 1217-1219.

Allen, D.N., Strauss, G.P., Donohue, B., van Kammen, D.P., 2007. Factor analytic support for social cognition as a separable cognitive domain in schizophrenia. Schizophr. Res. 93, 325-333.

Ambady, N., Hallahan, M., Rosenthal, R., 1995. On judging and being judged accurately in zero-acquaintance situations. J. Pers. Soc. Psychol. 69, 519-529.

Andia, A.M., Zisook, S., Heaton, R.K., Hesselink, J., Jernigan, T., Kuck, J., Morganville, J., Braff, D.L., 1995. Gender differences in schizophrenia. J. Nerv. Ment. Dis. 183, 522-528.

APA, 1980. Diagnostic and Statistical Manual of Mental Disorders, 3rd ed. American Psychiatric Association, Washington, DC.

APA, 1987. Diagnostic and Statistical Manual of Mental Disorders, 3rd rev. ed. American Psychiatric Association, Washington, DC.

APA, 1994. Diagnostic and Statistical Manual of Mental Disorders, 4th ed. American Psychiatric Association, Washington DC.

APA, 2000. Diagnostic and Statistical Manual of Mental Disorders, 4th rev. ed. American Psychiatric Association, Washington, DC.

Asarnow, R.F., Granholm, E., Sherman, T., 1991. Span of apprehension in schizophrenia. In: Steinhauer, S.R., Gruzelier, J.H., Zubin, J. (Eds.), Handbook of Schizophrenia, Neuropsychology, Psychophysiology and Information Processing. Elsevier, Amsterdam, The Netherlands.

Baker, R., Hall, J.N., 1988. REHAB: a new assessment instrument for chronic psychiatric patients. Schizophr. Bull. 14, 88-111.

Barker, S., Barron, N., Mcfarland, B.H., Bigelow, D.A., Carnahan, T., 1994. A community ability scale for chronically mentally ill consumers: part II. Applications. Community Ment. Health J. 30, 459-472.

Baron-Cohen, S., Wheelwright, S., Hill, J., Raste, Y., Plumb, I., 2001. The "Reading the Mind in the Eyes" Test revised version: a study with normal adults, and adults with Asperger syndrome or high functioning autism. J. Child Psychol. Psychiatry 42, 241-251.

Bech, P., 1993. Rating Scales for Psychopathology, Health Status and Quality of Life: a compendium on documentation in accordance with the DSM-III-R and WHO systems. Springer, Berlin.

Bell, M., Bryson, G., Lysaker, P., 1997. Positive and negative affect recognition in schizophrenia: a comparison with substance use and normal control subjects. Psychiatry Res. 73, 73-82.

Bell, M., Tsang, H.W.H., Greig, T.C., Bryson, G., 2009. Neurocognition, social cognition, perceived social discomfort, and vocational outcome in schizophrenia. Schizophr. Bull. 35, 738-747.

Bellack, A.S., Green, M.F., Cook, J.A., Fenton, W., Harvey, P.D., Heaton, R.K., Laughren, T., Leon, A.C., Mayo, D.J., Patrick, D.L., Patterson, T.L., Rose, A., Stover, E., Wykes, T., 2007. Assessment of community functioning in people with schizophrenia and other severe mental illnesses: a white paper based on an NIMH-sponsored workshop. Schizophr. Bull. 33, 805-822.

Bellack, A.S., Sayers, M., Mueser, K.T., Bennett, M., 1994. Evaluation of social problem solving in schizophrenia. J. Abnorm. Psychol. 103, 371-378.

Benedict, R.H., Groninger, L., 1995. Preliminary standardization and validation of a new visuospatial memory test with six alternate forms. Clin. Neuropsychol. 9, 11-16.

Benton, A.L., 1967. Problems of test construction in the field of aphasia. Cortex 3, 32-58.

Benton, S.A., 1992. Benton Visual Retention Test manual, 5 ed. Harcourt Brace \& Company, San Antonio.

Biehl, M., Matsumoto, D., Ekman, P., Hearn, V., 1997. Matsumoto and Ekman's Japanese and Caucasian Facial Expression and Emotion (JACFEE): reliability data and cross national differences. J. Nonverbal Behav. 21, 3-21.

Bilder, R., Ventura, J., Cienfuegos, A., 2003. Clinical Global Impression of Cognition in Schizophrenia (CGI-CogS) Manual and Rating Sheet. UCLA Department of Psychiatry, Los Angeles, California.

Birchwood, M., Smith, J., Cockrane, R., Wetton, S., Copestate, C., 1990. The Social Functioning Scale: the development and validation of a new scale of social adjustment for use in family intervention programmes with schizophrenia patients. Br. J. Psychiatry 157, 853-859.

Bolton, B., Roessler, R., 1986. The Work Personality Profile: factor scales, reliability, validity and norms. Vocat. Eval. Work Adjust. Bull. 19, 143-149.

Bora, E., Eryavuz, A., Kayahan, B., Sungu, G., Veznedaroglu, B., 2006. Social functioning, theory of mind and neurocognition in outpatients with schizophrenia; mental state decoding may be a better predictor of social functioning than mental state reasoning. Psychiatry Res. 145, 95-103.

Bora, E., Yücel, M., Pantelis, C., 2009. Theory of mind impairment: a distinct trait-marker for schizophrenia spectrum disorders and bipolar disorder? Acta Psychiatr. Scand. 120, 253-264.

Bowen, L., Wallace, C.J., Glynn, S.M., Nuechterlein, K.H., Lutzker, J.R., Kuehnel, T.G., 1994. Schizophrenic individuals' cognitive functioning and performance in interpersonal interactions and skills training procedures. J. Psychiatr. Res. 28, 289-301.

Bowers, D., Blonder, L.X., Heilman, K.M., 1991. Florida Affect Battery. Center for Neuropsychological Studies, University of Florida, Gainsville, FL.

Bozikas, V.P., Kosmidis, M.H., Kafantari, A., Gamvrula, K., Vasiliadou, E., Petrikis, P., Fokas, K., Karavatos, A., 2006. Community dysfunction in schizophrenia: rate-limiting factors. Prog. Neuropsychopharmacol. Biol. Psychiatry 30, 463470.

Brandt, J., 1991. The Hopkins Verbal Learning Test: development of a new memory test with six equivalent forms. Clin. Neuropsychol. 5, 125-142.

Brekke, J., Kay, D.D., Lee, K.S., Green, M.F., 2005. Biosocial pathways to functional outcome in schizophrenia. Schizophr. Res. 80, 213-225.

Brekke, J.S., Hoe, M., Long, J., Green, M.F., 2007. How neurocognition and social cognition influence functional change during community-based psychosocial rehabilitation for individuals with schizophrenia. Schizophr. Bull. 33, 1247-1256.

Brekke, J.S., Kohrt, B., Green, M.F., 2001. Neuropsychological functioning as a moderator of the relationship between psychosocial functioning and the subjective experience of self and life in schizophrenia. Schizophr. Bull. 27, 697-708.

Brickenkamp, R., 1978. Test d2 Aufmerksamkeits-Belastungs-Test. Hogrefe, Goettingen.

Bruene, M., 2003. Theory of mind and the role of IQ in chronic disorganized schizophrenia. Schizophr. Res. 60, 57-64.

Bruene, M., 2005. Emotion recognition, 'theory of mind' and social behavior in schizophrenia. Psychiatry Res. 133, 135-147.

Buchanan, R.W., Davis, M., Goff, D., Green, M.F., Keefe, R.S., Leon, A.C., Nuechterlein, K.H., Laughren, T., Levin, R., Stover, E., Fenton, W., Marder, S.R., 2005. A summary of the FDA-NIMH-MATRICS workshop on clinical trial design for neurocognitive drugs for schizophrenia. Schizophr. Bull. 31, 5-19.

Burns, T., Patrick, D., 2007. Social functioning as an outcome measure in schizophrenia studies. Acta Psychiatr. Scand. 116, 403-418.

Carlsson, R., Nyman, H., Ganse, G., Cullberg, J., 2006. Neuropsychological functions predict 1- and 3-year outcome in first-episode psychosis. Acta Psychiatr. Scand. $113,102-111$.

Carter, C.S., Barch, D.M., 2007. Cognitive neuroscience-based approaches to measuring and improving treatment effects on cognition in schizophrenia: the CNTRICS initiative. Schizophr. Bull. 33, 1131-1137.

Chapman, L., Chapman, J., 1978. The measurement of differential deficit. J. Psychiatr. Res. 14, 303-311. 
Cohen, A.S., Forbes, C.B., Mann, M.C., Blanchard, J.J., 2006. Specific cognitive deficits and differential domains of social functioning impairment in schizophrenia. Schizophr. Res. 81, 227-238.

Concoran, R., 2001. Theory of mind and schizophrenia. In: Corrigan, P.W., Penn, D.L. (Eds.), Social Cognition and Schizophrenia. American Psychological Association, Washington, DC, pp. 149-174.

Concoran, R., Mercer, G., Frith, C.D., 1995. Schizophrenia, symptomatology and social inference: investigating "theory of mind" in people with schizophrenia. Schizophr. Res. 17, 5-13.

Corrigan, P.W., Addis, I.B., 1995. The effect of cognitive complexity on a social sequencing task in schizophrenia. Schizophr. Res. 16, 137-144.

Corrigan, P.W., Buican, B., Toomey, R., 1996. Construct validity of two tests of social cognition in schizophrenia. Psychiatry Res. 63, 77-82.

Corrigan, P.W., Green, M.F., 1993a. Schizophrenic patients' sensitivity to social cues: the role of abstraction. Am. J. Psychiatry 150, 589-594.

Corrigan, P.W., Green, M.F., 1993b. The Situational Feature Recognition Test: a measure of schema comprehension for schizophrenia. Int. J. Method Psychol. 3, 29-35.

Corrigan, P.W., Toomey, R., 1995. Interpersonal problem solving and information processing in schizophrenia. Schizophr. Bull. 21, 395-403.

Corrigan, P.W., Wallace, C.J., Green, M.F., 1992. Deficits in social schemata in schizophrenia. Schizophr. Res. 8, 129-135.

Couture, S.M., Penn, D.L., Roberts, D.L., 2006. The functional significance of social cognition in schizophrenia: a review. Schizophr. Bull. 32 (Suppl. 1), S44-63.

Delis, D.C., Kramer, J.H., Kaplan, E., Ober, B.A., 1987. California Verbal Learning Test: Adult Version Manual. The Psychological Corporation, San Antonio, TX.

Dickerson, F., Boronow, J.J., Ringel, N., Parente, F., 1996. Neurocognitive deficits and social functioning in outpatients with schizophrenia. Schizophr. Res. 21, 75-83.

Dickerson, F., Boronow, J.J., Ringel, N., Parente, F., 1999. Social functioning and neurocognitive deficits in outpatients with schizophrenia: a 2-year follow-up. Schizophr. Res. 37, 13-20.

Diller, L., Ben-Yishay, Y., Gerstman, L.J., Goodkin, R., Gordon, W., Weinberg, J., 1974. Studies in cognition and rehabilitation in hemiplegia. Rehabilitation Monograph. New York Medical Center Institute of Rehabilitation Medicine, New York.

Dominguez, M.G., Viechtbauer, W., Simons, C., Van Os, J., Krabbendam, L., 2009. Are psychotic psychopathology and neurocognition orthogonal? A systematic review of their associations. Psychol. Bull. 135, 157-171.

Donahoe, C.P., Carter, M.J., Bloem, W.D., Leff, G.L., 1990. Assessment of interpersonal problem-solving skills. Psychiatry 53, 515-525.

Eack, S.M., Keshavan, M.S., 2008. Foresight in schizophrenia: a potentially unique and relevant factor to functional disability. Psychiatr. Serv. 59, 256-260.

Ekman, P., Friesen, W.V., 1976. Pictures of Facial Affect. Consulting Psychologists Press, Palo Alto, CA.

Endicott, J., Spitzer, R.L., 1978. A diagnostic review: The Schedule for Affective Disorders and Schizophrenia. Arch. Gen. Psychiatry 35, 837-844.

Endicott, J., Spitzer, R.L., Fleiss, J.L., Cohen, J., 1976. The Global Assessment Scale. Arch. Gen. Psychiatry 33, 766-771.

Fiszdon, J.M., Choi, J., Goulet, J., Bell, M.D., 2008. Temporal relationship between change in cognition and change in functioning in schizophrenia. Schizophr. Res. $105,105-113$.

Flashman, L.A., Green, M.F., 2004. Review of cognition and brain structure in schizophrenia: profiles, longitudinal course, and effects of treatment. Psychiatr. Clin. N. Am. 27, 1-18.

Gard, D.E., Fisher, M., Garrett, C., Genevsky, A., Vinogradov, S., 2009. Motivation and its relationship to neurocognition, social cognition and functional outcome in schizophrenia. Schizophr. Res. 115, 74-81.

Gold, J.M., 2004. Cognitive deficits as treatment targets in schizophrenia. Schizophr. Res. 72, 21-28.

Goodman, S.H., Sewell, D.R., Cooley, E.L., Leavitt, N., 1993. Assessing levels of adaptive functioning: The Role Functioning Scale. Community Ment. Health J. 29, 119-131.

Green, M.F., 1996. What are the functional consequences of neurocognitive deficits in schizophrenia? Am. J. Psychiatry 153, 321-330.

Green, M.F., Kern, R.S., Braff, D.L., Mintz, J., 2000. Neurocognitive deficits and functional outcome in schizophrenia: are we measuring the "right stuff"? Schizophr. Bull. 26, 119-136.

Green, M.F., Kern, R.S., Heaton, R.K., 2004a. Longitudinal studies of cognition and functional outcome in schizophrenia: implications for MATRICS. Schizophr. Res. $72,41-51$

Green, M.F., Nuechterlein, K.H., Breitmeyer, B., Tsuang, J., Mintz, J., 2003. Forward and backward masking in schizophrenia: influence of age. Psychol. Med. 33, 887-895.

Green, M.F., Nuechterlein, K.H., Gold, J.M., Barch, D.M., Cohen, J., Essock, S., Fenton, W.S., Frese, F., Goldberg, T.E., Heaton, R. K, Keefe, R.S, Kern, R.S., Kraemer, H. Stover, E., Weinberger, D.R., Zalcman, S., Marder, S.R., 2004b. Approaching a consensus cognitive battery for clinical trials in schizophrenia: the NIMH-MATRICS conference to select cognitive domains and test criteria. Biol. Psychiatry 56, 301-307.

Green, M.F., Olivier, B., Crawley, J.N., Penn, D.L., Silverstein, S., 2005. Social cognition in schizophrenia: recommendations from the measurement and treatment research to improve cognition in schizophrenia new approaches conference. Schizophr. Bull. 31, 827-882.

Green, M.F., Penn, D.L., Bentall, R., Carpenter, W.T., Gaebel, W., Ruben, G.C., Kring, A.M., Park, S., Silverstein, M., Heinssen, R., 2008. Social cognition in schizophrenia: an NIMH workshop on definitions, assessment, and research opportunities. Schizophr. Bull. 34, 1211-1220.
Harvey, P.D., Bellack, A.S., 2009. Toward a terminology for functional recovery in schizophrenia: is functional remission a viable concept? Schizophr. Bull. 35, 300-306.

Harvey, P.D., Green, M.F., Keefe, R.S., Velligan, D.I., 2004. Cognitive functioning in schizophrenia: a consensus statement on its role in the definition and evaluation of effective treatments for the illness. J. Clin. Psychiatry 65, 361-372.

Harvey, P.D., Velligan, D.I., Bellack, A.S., 2007. Performance-based measures of functional skills: usefulness in clinical treatment studies. Schizophr. Bull. 33 1138-1148.

Hatashita Wong, M., Smith, T.E., Silverstein, S.M., Hull, J.W., Willson, D.F., 2002. Cognitive functioning and social problem-solving skills in schizophrenia. Cognit. Neuropsychiatry 7, 81-95.

Heaton, R.K., 1981. A manual for the Wisconsin Card Sorting Test. Psychologica Assessment Resources, Odessa, Florida.

Hedges, L.V., Vevea, J.L., 1998. Fixed- and random-effects models in meta-analysis Psychol. Methods 3, 486-504.

Heinrichs, D.W., Hanlon, T.E., Carpenter, W.T., 1984. The Quality of Life Scale: an instrument for rating the schizophrenic deficit syndrome. Schizophr. Bull. 10 388-398.

Heinrichs, D.W., Zakzanis, K.K., 1998. Neurocognitive deficit in schizophrenia: a quantitative review of the evidence. Neuropsychology 12, 426-445.

Hofer, A., Baumgartner, S., Bodner, T., Edlinger, M., Hummer, M., Kemmler, G., Rettenbacher, M.A., Fleischhacker, W.W., 2005. Patient outcomes in schizophrenia II: the impact of cognition. Eur. Psychiatry 20, 395-402.

Hogarty, G.E., Flesher, S., Ulrich, R., Carter, M., Greenwald, D., Pogue-Geile, M., Kechavan, M., Cooley, S., DiBarry, A.L., Garrett, A., Parepally, H., Zoretich, R., 2008 Cognitive enhancement therapy for schizophrenia: effects of a 2 year randomized trial on cognition and behavior. Arch. Gen. Psychiatry 61, 866-876.

Holthausen, E.A., Wiersma, D., Cahn, W., Kahn, R.S., Dingemans, P.M., Schene, A.H. van den Bosch, R.J., 2007. Predictive value of cognition for different domains of outcome in recent-onset schizophrenia. Psychiatry Res. 149, 71-80.

Honigfeld, R., Roderic, D., Klett, J.C., 1966. NOSIE-30: a treatment sensitive ward behavior scale. Psychol. Rep. 19, 180-182.

Hooker, C., Park, S., 2002. Emotion processing and its relationship to social functioning in schizophrenia patients. Psychiatry Res. 112, 41-50.

Horan, W.P., Kern, R.S., Green, M.F., Penn, D.L., 2008. Social cognition training for individuals with schizophrenia: emerging evidence. Am. J. Psychiatric Rehabil. $11,205-252$.

Horan, W.P., Kern, R.S., Shokat-Fadai, K., Sergi, M.., Wynn, J.K., Green, M.F., 2009. Social cognitive skills training in schizophrenia: an initial efficacy study of stabilized outpatients. Schizophr. Res. 107, 47-54.

Horton, H.K., 2005. Schizophrenia, deafness, and functional outcome: the role of neurocognition and social cognition. Dissert. Abst. Int. Section A: Hum. Social Sci. 66, 1163.

Horton, H.K., Silverstein, S.M., 2007. Cognition and functional outcome among dea and hearing people with schizophrenia. Schizophr. Res. 94, 187-196.

Ihnen, G.H., Penn, D.L., Corrigan, P.W., Martin, J., 1998. Social perception and socia skill in schizophrenia. Psychiatry Res. 80, 275-286.

Ikebuchi, E., 2007. Social skills and social and nonsocial cognitive functioning in schizophrenia. J. Mental Health 16, 581-594.

IPA, 2002. IDEAS (Indian Disability Evaluation and Assessment Scale)-A Scale For Measuring and Quantifying Disability in Mental Disorders. Indian Psychiatric Society, Chennai.

Iwasaki, S., Miyauchi, M., Oshima, I., Murata, N., Nonaka, T., Kato, H., et al., 1994. The development of Life Assessment Scale for the Mentally Ill: an assessment of the reliability. Seishin Igaku (Clinical Psychiatry) 36, 1139-1151.

Jonides, J., Nee, D.E., 2005. Assessing dysfunction using refined cognitive methods Schizophr. Bull. 31, 823-829.

Kee, K.S., Green, M.F., Mintz, J., Brekke, J.S., 2003. Is emotion processing a predictor of functional outcome in schizophrenia? Schizophr. Bull. 29, 487-497.

Kee, K.S., Horan, W.P., Salovey, P., Kern, R.S., Sergi, M.J., Fiske, A.P., Lee, J., Subotnik, K.L., Nuechterlein, K.H., Sugar, C.A., Green, M.F., 2009. Emotional intelligence in schizophrenia. Schizophr. Res. 107, 61-68.

Keefe, R., 1999. Brief Assessment of Cognition in Schizophrenia: BACS Manual, Version 2.1. Duke University Medical Center, Durham, NC.

Keefe, R., Bilder, R., Harvey, P.D., Davis, S.M., Palmer, B.W., Gold, J.M., Meltzer, H.Y., Green, M.F., Miller, D.D., Canive, J.M., Adler, L.W., Manschreck, T.C., Swartz, M., Rosenheck, R., Perkins, D.O., Walker, T.M., Stroup, T.S., McEvoy, J.P., Lieberman, J., 2006a. Baseline neurocognitive deficits in the CATIE schizophrenia trial. Neuropsychopharmacology 31, 2033-2046.

Keefe, R.S., Goldberg, T.E., Harvey, P.D., Gold, J.M., Poe, M., Coughenour, L., 2004. The Brief Assessment of Cognition in Schizophrenia: reliability, sensitivity, and comparison with a standard neurocognitive battery. Schizophr. Res. 68, 283-297.

Keefe, R.S., Poe, M., Walker, T.M., Harvey, P.D., 2006b. The relationship of the Brief Assessment of Cognition in Schizophrenia (BACS) to functional capacity and real-world functional outcome. J. Clin. Exp. Neuropsychol. 28, 260-269.

Keefe, R.S., Poe, M., Walker, T.M., Kang, J.W., Harvey, P.D., 2006c. The Schizophrenia Cognition Rating Scale: an interview-based assessment and its relationship to cognition, real-world functioning, and functional capacity. Am. J. Psychiatry 163 , 426-432.

Kerr, S.L., Neale, J.M., 1993. Emotion perception in schizophrenia: specific deficit or further evidence of generalized poor performance? J. Abnorm. Psychol. 102 312-318

Koren, D., Seidman, L.J., Goldsmith, M., Harvey, P.D., 2006. Real-world cognitive - and metacognitive - dysfunction in schizophrenia: a new approach for measuring (and remediating) more "right stuff". Schizophr. Bull. 32, 310-326. 
Krishnadas, R., Moore, B.P., Nayak, A., Patel, R.R., 2007. Relationship of cognitive function in patients with schizophrenia in remission to disability: a cross-sectional study in an Indian sample. Ann. Gen. Psychiatry 6.

Kurtz, M.M., Ragland, J.D., Bilker, W., Gur, R.C., Gur, R.E., 2001. Comparison of the Continuous Performance Test with and without working memory demands in healthy controls and patients with schizophrenia. Schizophr. Res. 48, 307-316.

Kurtz, M.M., Ragland, J.D., Moberg, P.J., Gur, R.C., 2004. The Penn Conditional Exclusion Test: a new measure of executive function with alternate forms of repeat administration. Arch. Clin. Neuropsychol. 19, 191-201.

Laes, J.R., Sponheim, S.R., 2006. Does cognition predict community function only in schizophrenia? A study of schizophrenia patients, bipolar affective disorder patients, and community control subjects. Schizophr. Res. 84, 121-131.

Lehman, A.F., 1997. Lehman Work and Productive Activity Scale.

Lehmann, A.F., 1989. A quality of life interview for the chronically mentally ill. Eval. Program. Plann. 11, 51-62.

Lehrl, S., 1976. Der MWT-ein Intelligenztest fuer die Aerztliche Praxis. Neurologie und Psychiatrie 7, 488-491.

Leifker, F.R., Patterson, R., Heaton, K., Harvey, P.D., 2009. Validating measures of real-world outcome: the results of the VALERO expert survey and RAND panel. Schizophr. Bull. 35, 311-312.

Leucht, S., Kissling, W., Davis, D.M., 2009. How to read and understand and use systematic reviews and meta-analyses. Acta Psychiatr. Scand. 119, 443-450.

Luteijn, F., Bardels, D., 2004. Groningen Intelligence Test 2 (GIT-2): Manual. Harcourt Assessment BV, Amsterdam, The Netherlands.

Lysaker, P.H., Davis, L.W., 2004. Social function in schizophrenia and schizoaffective disorder: associations with personality, symptoms and neurocognition. Health Qual. Life Outcomes 2, 15.

Lysaker, P.H., Lancaster, R.S., Nees, M.A., Davis, L.W., 2004. Attributional style and symptoms as predictors of social function in schizophrenia. J. Rehabil. Res. Dev. 41, 225-232.

Mayer, J.D., Salovey, P., Caruso, D.R., 2002. Mayer-Salovey-Caruso Emotional Intelligence Test (MSCEIT): User's Manual. Multi-Health Systems, Inc., Toronto, Ontario.

McGurk, S.R., Twamley, E.W., Sitzer, D.I., McHugo, G.J., Mueser, K.T., 2007. A metaanalysis of cognitive remediation in schizophrenia. Am. J. Psychiatry 164, 11791-11802.

Menditto, A.A., Wallace, C.J., Liberman, R.P., Robert, P., Van der Wal, J., Jones, N.T., Stuve, P., 1999. Functional assessment of independent living skills. Psychiatric Rehabil. Skills 3, 200-219.

Meyer, M.B., Kurtz, M.M., 2009. Elementary neurocognitive function, facial affect recognition and social-skills in schizophrenia. Schizophr. Res. 110, 173-179.

Milev, P., Ho, B.C., Arndt, S., Andreasen, N.C., 2005. Predictive values of neurocog nition and negative symptoms on functional outcome in schizophrenia: a longitudinal first-episode study with 7-year follow-up. Am. J. Psychiatry 162 495-506.

Miller, M.B., Chapman, J.P., Chapman, L.J., Collins, J., 1995. Task difficulty and cognitive deficits in schizophrenia. J. Abnorm. Psychol. 104, 251-258.

Mueser, K.T., Bellack, A.S., Douglas, M.S., Wade, J.H., 1991. Prediction of social skill acquisition in schizophrenic and major affective disorder patients from memory and symptomatology. Psychiatry Res. 37, 281-296.

Mueser, K.T., Bellack, A.S., Wade, J.H., Sayers, S.L., Tierney, A., Haas, G., 1993 Expressed emotion, social skill, and response to negative affect in schizophrenia. J. Abnorm. Psychol. 102, 339-351.

Mueser, K.T., Blanchard, J.J., Bellack, A.S., 1995. Memory and social skill in schizophrenia: the role of gender. Psychiatry Res. 57, 141-153.

Mueser, K.T., Doonan, R., Penn, D.L., Blanchard, J.J., Bellack, A.S., Nishith, P., DeLeon, J., 1996. Emotion recognition and social competence in chronic schizophrenia. J. Abnorm. Psychol. 105, 271-275.

Munroe-Blum, H., Collins, E., McCleary, L., Nutall, S., 1996. The social dysfunction index for patients with schizophrenia and related disorders. Schizophr. Res. 20 , 211-219.

Nakagami, E., Xie, B., Hoe, M., Brekke, J.S., 2008. Intrinsic motivation, neurocognition and psychosocial functioning in schizophrenia: testing mediator and moderator effects. Schizophr. Res. 105, 95-104.

Nelson, H.E., 1976. A modified card sorting test sensitive to frontal lobe defects. Cortex 12.

Nemoto, T., Kashima, H., Mizuno, M., 2007. Contribution of divergent thinking to community functioning in schizophrenia. Prog. Neuropsychopharmacol. Biol Psychiatry 31, 517-524.

Nowicki, S., Duke, M.P., 1994. Individual differences in the nonverbal communication of affect: the diagnostic analysis of nonverbal accuracy scale. J. Nonverbal Behav. $18,9-35$

Nuechterlein, K.H., Asarnow, R.F., 1992. Manual and Computer Program for the UCLA Continuous Performance Test: Version 4. University of California, LA, Los Angeles.

Nuechterlein, K.H., Barch, D.M., Gold, J.M., Goldberg, T.E., Green, M.F., Heaton, R.K., 2004. Identification of separable cognitive factors in schizophrenia. Schizophr. Res. 72, 29-39.

Nuechterlein, K.H., Dawson, M.E., 1984. A heuristic vulnerability/stress model of schizophrenic episodes. Schizophr. Bull. 10, 300-312.

Olthmanns, T.F., Neale, J.M., 1975. Schizophrenic performance when distractors are present: attentional deficit or differential task difficulty? J. Abnorm. Psychol. 84, 205-209.

Patterson, T.L., Goldman, S., McKibbin, C.L., Hughs, T., Jeste, D.V., 2001a. UCSD Performance -Based Skills Assessment: development of a new measure of everyday functioning for severely mentally ill adults. Schizophr. Bull. 27, 235-245.
Patterson, T.L., Moscona, S., McKibbin, C.L., Davidson, K., Jeste, D.V., 2001b. Social skills performance assessment among older patients with schizophrenia. Schizophr. Res. 48, 351-360.

Penn, D.L., Corrigan, P.W., Bentall, R.P., Racenstein, J.M., Newman, L., 1997. Social cognition in schizophrenia. Psychol. Bull. 121, 114-132.

Penn, D.L., Mueser, K.T., Doonan, R., Nishith, P., 1995a. Relations between social skills and ward behavior in chronic schizophrenia. Schizophr. Res. 16, 225-232.

Penn, D.L., Mueser, K.T., Spaulding, W., 1996a. Information processing, social skill, and gender in schizophrenia. Psychiatry Res. 59, 213-220.

Penn, D.L., Mueser, K.T., Spaulding, W., Hope, D.A., Reed, D., 1995b. Information processing and social competence in chronic schizophrenia. Schizophr. Bull. 21, 269-281.

Penn, D.L., Sanna, L.J., Roberts, D.L., 2008. Social cognition in schizophrenia: an overview. Schizophr. Bull. 34, 408-411.

Penn, D.L., Spaulding, W., Reed, D., Sullivan, M., 1996b. The relationship of social cognition to ward behavior in chronic schizophrenia. Schizophr. Res. 20, 327-335.

Pijnenborg, G.H.M., Withaar, F.K., Evans, J.J., Van den Bosch, R.J., Timmerman, M.E. Brouwer, W.H., 2009. The predictive value of measures of social cognition fo community functioning in schizophrenia: implications for neuropsychological assessment. J. Int. Neuropsychol. Soc. 15, 239-247.

Pijnenborg, G.H.M., Withaar, F.K., van den Bosch, R.J., Brouwer, W.H., 2007. Impaired perception of negative emotional prosody. Clin. Neuropsychol. 52, 236-240.

Pinkham, A.E., Penn, D.L., 2006. Neurocognitive and social cognitive predictors of interpersonal skill in schizophrenia. Psychiatry Res. 143, 167-178.

Pinkham, A.E., Penn, D.L., Perkins, D.O., Lieberman, J., 2003. Implications for the neural basis of social cognition for the study of schizophrenia. Am. J. Psychiatry 160 , 815-824.

Poole, J.H., Ober, B.A., Shenaut, G.K., Vinogradov, S., 1999. Independent frontalsystem deficits in schizophrenia: cognitive, clinical, and adaptive implications. Psychiatry Res. 85, 161-176.

Poole, J.H., Tobias, F.C., Vinogradov, S., 2000. The functional relevance of affect recognition errors in schizophrenia. J. Int. Neuropsychol. Soc. 6, 649-658.

Raudenbush, S.W., 1994. Random effects models. In: Cooper, H.M., H.L. (Eds.), The Handbook of Research Synthesis. Russell Sage, New York, pp. 301-321.

Raven, J.C., 1958. Guide to using the Coloured Progressive Matrices. H. K. Lewis \& Co., Oxford, England.

Reitan, R.M., 1958. Validity of the Trail Making Test as an indication of organic brain damage. Percept. Mot. Skills 8, 271-276.

Revheim, N., Medalia, A., 2004. Verbal memory, problem-solving skills and community status in schizophrenia. Schizophr. Res. 68, 149-158.

Revheim, N., Schechter, I., Kim, D., Silipo, G., Allingham, B., Butler, P., Javitt, D.C. 2006. Neurocognitive and symptom correlates of daily problem-solving skills in schizophrenia. Schizophr. Res. 83, 237-245.

Rey, A., 1941. L'examen psychologique dans les cas d'encephalopathie traumatique: les problèmes (The Psychological Examination in Cases of Traumatic Encephalopathy: Problems). Archives de Psychologie 28, 215-285.

Rey, A., 1964. L'examen Clinique en Psychologie (Clinical Assessment in Psychology) Presses Universitaires de France, Paris.

Roberts, D.L., Penn, D.L., 2010. Social Cognition and Intervention Training (SCIT) for outpatients with schizophrenia: a preliminary study. Behav. Cogn. Psychother. $38,35-47$.

Robertson, I.H., Ward, T., Ridgeway, V., Nimmo-Smith, I., 1994. The Test of Everyday Attention. Thames Valley Test Company, Bury St Edmunds, UK.

Rosen, A., Parker, G., Hadzi-Pavlovic, D., Hartley, R., 1987. The Life Skills Profile: a measure of assessing function and disability in schizophrenia. Schizophr. Bull. $15,325-337$.

Saan, R.J., Deelman, B.G., 1986. De 15-Woorden Tests A (manual). AZG afdeling neuropsychologie, Groningen.

Savilla, K., Kettler, L., Galletly, C., 2008. Relationships between cognitive deficits symptoms and quality of life in schizophrenia. Aust. N. Z. J. Psychiatry 42 496-504.

Sayers, M., Bellack, A.S., Wade, J.H., Bennett, M., Fong, P., 1995. An empirical method for assessing social problem solving in schizophrenia. Behav. Modif 19, 267-290.

Schennach-Wolff, R., Jäger, M., Seemüller, F., Michael Obermeier, M., Messer, T., Laux G., Pfeiffer, H., Naber, D., Schmidt, L.G., Gaebel, W., Huff, W., Heuser, I., Maier, W., Lemke, M.R., Rüther, E., Buchkremer, G., Gastpar, M., Möller, H., Riedel, M., 2009. Defining and predicting functional outcome in schizophrenia and schizophrenia spectrum disorders. Schizophr. Res. 113, 210-217.

Schooler, N.H., Weissman, G., Hogarty, G., 1979. Social Adjustment Scale for Schizophrenics. In: Hargreaves, W.A., Attkisson, C.C., Sorenson, J. (Eds.), Resource Materials for Community Mental Health Program Evaluators. National Institute of Mental Health, Rockville, MD.

Sergi, M.J., Rassovsky, Y., Nuechterlein, K.H., Green, M.F., 2006. Social perception as a mediator of the influence of early visual processing on functional status in schizophrenia. Am. J. Psychiatry 163, 448-454

Sergi, M.J., Rassovsky, Y., Widmark, C., Reist, C., Erhart, S., Braff, D.L., Marder, S.R. Green, M.F., 2007. Social cognition in schizophrenia: relationships with neurocognition and negative symptoms. Schizophr. Res. 90, 316-324.

Shipley, W.C., 1991. Shipley Institute of Living Scale. Western Psychological Services, Los Angeles.

Skantze, K., Malm, U., 1994. A new approach to facilitation of working alliances based on patients' quality of life goals. Nord. J. Psychiatry 48, 37-49.

Smith, T.E., Hull, J.W., Goodman, M., Hedayat Harris, A., Willson, D.F., Israel, L.M., Munich, R.L., 1999. The relative influences of symptoms, insight, and neurocognition on social adjustment in schizophrenia and schizoaffective disorder. J. Nerv. Ment. Dis. 187, 102-108. 
Smith, T.E., Hull, J.W., Huppert, J.D., Silverstein, S.M., 2002. Recovery from psychosis in schizophrenia and schizoaffective disorder: symptoms and neurocognitive rate-limiters for the development of social behavior skills. Schizophr. Res. 55, 229-237.

Spaulding, W.D., Garbin, C.P., Dras, S.R., 1989. Cognitive abnormalities in schizophrenic patients. J. Nerv. Ment. Dis. 177, 717-723.

Spitzer, R.L., Endicott, J., Robins, E., 1978. Research diagnostic criteria: rationale and reliability. Arch. Gen. Psychiatry 35, 773-782.

Steiger, J.H., 1980. Test for comparing elements of a correlation matrix. Psychol. Bull. $87,245-251$

Sterne, J., Egger, M., 2005. Regression methods to detect publication and other bias in meta-analysis. In: Rothstein, H.R., A.J.S., Borenstein, M. (Eds.), Publication Bias in Meta-analysis: Prevention, Assessment and Adjustments. Wiley, New York, pp. 99-110.

Stewart, S.L.K., Corcoran, R., Drake, R.J., 2009. Mental state references in psychosis: a pilot study of prompted implicit mentalising during dialogue and its relationship with social functioning. Cognit. Neuropsychiatry 14, 53-75.

Stone, V.E., Baron-Cohen, S., Calder, A.W., Keane, J., 1998. Impairment in social cognition following orbitofrontal or amygdala damage. Soc. Neurosci. Abst. 24, 1176.

Stratta, P., Daneluzzo, E., Riccardi, I., Bustini, M., Rossi, A., 2009. Metacognitive ability and social functioning are related in persons with schizophrenic disorder. Schizophr. Res. 108, 301-302.

Test, M.A., Knoedler, W.H., Allness, D.J., Burke, S.S., Brown, R.L., Wallisch, L.S., 1991. Long-term community care through an assertive continuous treatment team. In: Tamminga, C., Schultz, S. (Eds.), Advances in Neuropsychiatry and Psychopharmacology. Raven Press, New York.

Tyson, P.J., Laws, K.R., Flowers, K.A., Schulz, J., Mortimer, A.M., 2008. Attention and executive function in people with schizophrenia: relationship with social skills and quality of life. Int. J. Psychiatry Clin. Pract. 12, 112-119.

Van Beilen, M., Kiers, H.A., Bou, A., Van Zomeren, E.H., Withaar, F.K., Arends, J., Van den Bosch, R.J., 2003. Cognitive deficits and social functioning in schizophrenia: a clinical perspective. Clin. Neuropsychol. 17, 507-514.

Van Hooren, S., Versmissen, D., Janssen, I., Myin-Germeys, I., A Campo, J., Mengelers, R., Van Os, J., Krabbendam, L., 2008. Social cognition and neurocognition as independent domains in psychosis. Schizophr. Res. 103, 257265.

Van Os, J., Wright, R., Murray, R., 1997. Follow-up studies of schizophrenia I: natural history and non-psychopathological predictors of outcome. Eur. Psychiatry 12, 327-341.

Vaskinn, A., Sundet, K., Friis, S., Simonsen, C., Birkenaes, A.B., Jonsdottir, H., Ringen, P.A., Andreassen, O.A., 2008. Emotion perception and learning potential: mediators between neurocognition and social problem-solving in schizophrenia? J. Int. Neuropsychol. Soc. 14, 279-288.

Vaskinn, A., Sundet, K., Hultman, C.M., Friis, S., Andreassen, O.A., 2009. Social problem-solving in high-functioning schizophrenia: specific deficits in sending skills. Psychiatry Res. 165, 215-223.

Vauth, R., Rusch, N., Wirtz, M., Corrigan, P.W., 2004. Does social cognition influence the relation between neurocognitive deficits and vocational functioning in schizophrenia? Psychiatry Res. 128, 155-165.
Velligan, D.I., DiCocco, M., Bow Thomas, C.C., Cadle, C., Glahn, D.C., Miller, A.L., Biggs, M.M., Shores Wilson, K., McKenzie, C.A., Crismon, M.L., 2004. A brief cognitive assessment for use with schizophrenia patients in community clinics. Schizophr. Res. 71, 273-283.

Velligan, D.I., Mahurin, R.K., Diamond, P.L., Hazleton, B.C., Eckert, S.L., Miller, A.L. 1997. The functional significance of symptomatology and cognitive function in schizophrenia. Schizophr. Res. 25, 21-31.

Ventura, J., Cienfuegos, A., Boxer, O., Bilder, R., 2008. Clinical Global Impression of Cognition in Schizophrenia (CGI-CogS): reliability and validity of a co-primary measure of cognition. Schizophr. Res. 106, 59-69.

Ventura, J., Hellemann, G.S., Thames, A.D., Koellner, V., Nuechterlein, K.H., 2009. Symptoms as mediators of the relationship between neurocognition and functional outcome in schizophrenia: a meta-analysis. Schizophr. Res. 113, 189-199.

Villalta Gil, V., Vilaplana, M., Ochoa, S., Haro, J.M., Dolz, M., Usall, J., Cervilla, J. 2006. Neurocognitive performance and negative symptoms: are they equal in explaining disability in schizophrenia outpatients? Schizophr. Res. 87, 246-253.

Waltheter, E.J., Jones, N.T., Johnson, E.R., Penn, D.L., 2005. Utility of social cognition and insight in the prediction of inpatient violence among individuals with a severe mental illness. J. Nerv. Ment. Dis. 193, 609-618.

Wechsler, D., 1955. Wechsler Adult Intelligence Scale. Psychological Corporation, New York.

Wechsler, D., 1981. Wechsler Adult Intelligence Scale-Revised. Psychological Corporation, New York.

Wechsler, D., 1987. Wechsler Memory Scale-Revised. The Psychological Corporation, New York.

WHO, 1977. International Classification of Diseases, 9th, rev. ed. World Health Organization, Geneva, Switzerland.

WHO, 1988. Psychiatric Disability Assessment Schedule (WHO/DAS). World Health Organization Geneva, Switzerland.

WHO, 1990. International Classification of Diseases, 10th rev. ed. World Health Organization, Geneva, Switzerland.

Wiersma, D., De Jong, A., Ormel, J., 1988. The Groningen Social Disabilities Schedule: development, relationship with I.C.I.D.H., and psychometric properties. Int. J Rehabil. Res. 11, 213-224.

Wilkinson, G.S., 1993. WRAT3; Wide Range Achievement Test. Jastak Association, Wilmington, DE.

Wilson, B.A., Alderman, N., Burgess, P.W., Emslie, H., Evans, J.J., 1996. Behavioral Assessment of the Dysexecutive Syndrome. Bury St. Edmunds, UK.

Woonings, F.M., Appelo, M.T., Kluiter, H., Slooff, C.J., van den Bosch, R.J., 2002 Learning (potential) and social functioning in schizophrenia. Schizophr. Res. 59 287-296.

Wykes, T., Sturt, E., 1986. The measurement of social behaviour in psychiatric patients: an assessment of the reliability and validity of the SBS schedule. Br. J. Psychiatry 148, 1-11.

Young, A.W., Perrett, D., Calder, A., Sprengelmeyer, R., Ekman, P., 2002. The Facial Expressions of Emotion: Stimuli and Test, Manual. Edmunds, UK.

Zanello, A., Perrig, L., Huguelet, P., 2006. Cognitive functions related to interpersonal problem-solving skills in schizophrenic patients compared with healthy subjects. Psychiatry Res. 142, 67-78. 